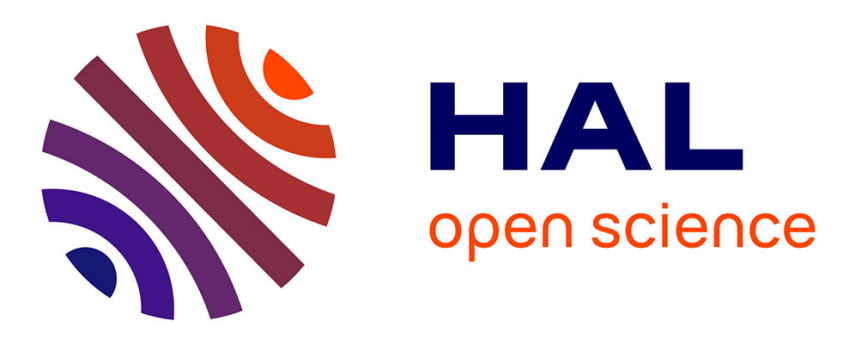

\title{
Temporal and spectral variation of desert dust and biomass burning aerosol scenes from 1995?2000 using GOME
}

\author{
M. de Graaf, P. Stammes, I. Aben
}

\section{- To cite this version:}

M. de Graaf, P. Stammes, I. Aben. Temporal and spectral variation of desert dust and biomass burning aerosol scenes from 1995?2000 using GOME. Atmospheric Chemistry and Physics Discussions, 2006, 6 (1), pp.1321-1353. hal-00300998

\section{HAL Id: hal-00300998 \\ https://hal.science/hal-00300998}

Submitted on 20 Feb 2006

HAL is a multi-disciplinary open access archive for the deposit and dissemination of scientific research documents, whether they are published or not. The documents may come from teaching and research institutions in France or abroad, or from public or private research centers.
L'archive ouverte pluridisciplinaire HAL, est destinée au dépôt et à la diffusion de documents scientifiques de niveau recherche, publiés ou non, émanant des établissements d'enseignement et de recherche français ou étrangers, des laboratoires publics ou privés. 


\section{GOME temporal and spectral aerosol \\ variation \\ M. de Graaf et al.}

\section{Temporal and spectral variation of desert dust and biomass burning aerosol scenes from 1995-2000 using GOME}

M. de Graaf ${ }^{1}$, P. Stammes ${ }^{1}$, and I. Aben ${ }^{2}$

${ }^{1}$ Royal Netherlands Meteorological Institute (KNMI), Wilhelminalaan 10, 3732 GK De Bilt, The Netherlands

${ }^{2}$ Netherlands Institute for Space Research (SRON), Sorbonnelaan 2, 3584 CA Utrecht, The Netherlands

Received: 9 November 2005 - Accepted: 20 December 2005 - Published: 20 February 2006 Correspondence to: M. de Graaf (graafdem@knmi.nl)

(C) 2006 Author(s). This work is licensed under a Creative Commons License.

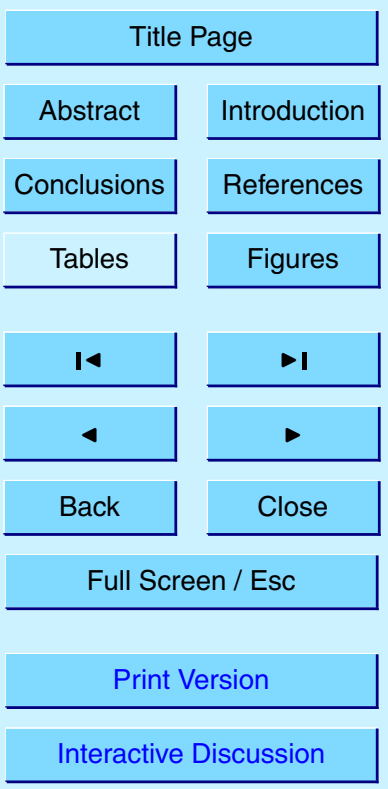




\section{Abstract}

Global Ozone Monitoring Experiment (GOME) Absorbing Aerosol Index (AAI) and AAI-related residue data were used to investigate areas with UV-absorbing aerosols. Time series of regionally averaged residues show the seasonal variation and trends 5 of aerosols and clouds in climatologically important parts of the globe. GOME spectra were used to study scenes containing specific types of aerosols. AAl data are specifically sensitive to biomass burning aerosols (BBA) and desert dust aerosols (DDA). Areas where these aerosols are regularly found were analysed to find spectral fingerprints in the ultraviolet (UV), visible and near-infrared (near-IR), to establish an aerosol

classification of BBA and DDA. Spectral residues are different for BBA and DDA, but over deserts the surface albedo is dominant beyond the UV and spectral residues cannot be used over land. Over oceans, about half of the BBA scenes show a very high reflectance that is never observed for DDA scenes. However, in the case of low reflectance scenes BBA and DDA cannot be distinguished. This is in part due to the 15 microphysical and optical properties of biomass burning aerosols, which are highly variable in time, making it difficult to specify them spectrally as one type. Because of their high hygroscopicity BBA are often found in the presence of clouds, which disturb the spectrum of the scenes. Desert dust aerosols are much less hygroscopic and behave spectrally more uniformly.

\section{1. Introduction}

The Absorbing Aerosol Index (AAI) (Herman et al., 1997; Torres et al., 1998; De Graaf et al., 2005) record is well-known as the longest record of global aerosol measurements currently available and the AAI has been used to indicate UV-absorbing aerosols, starting with Total Ozone Mapping Spectrometer (TOMS) data in 1978. Several new in(De Graaf et al., 2005), SCanning Imaging Absorption SpectroMeter for Atmospheric

ACPD

$6,1321-1353,2006$

GOME temporal and spectral aerosol variation

M. de Graaf et al.

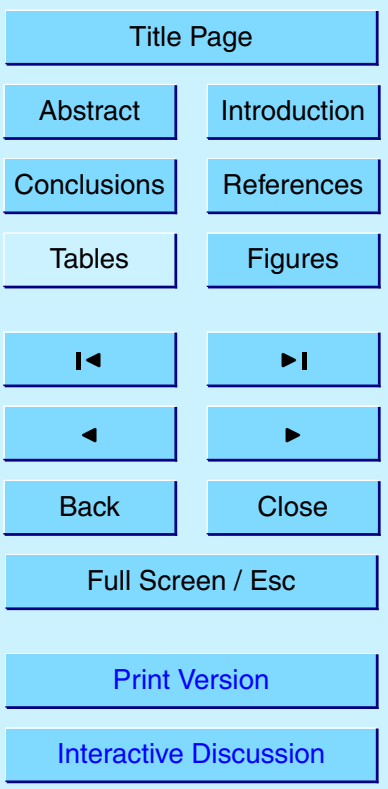

EGU 
CartograpHY (SCIAMACHY) (De Graaf and Stammes, 2005) and Ozone Monitoring Instrument (OMI) (Torres et al., 2001). The AAI can be regarded as the colour of a scene, at two UV wavelengths (usually 340 and $380 \mathrm{~nm}$ ), as compared to the colour of a pure Rayleigh atmosphere. Its greatest advantage is the applicability over both 5 land and oceans and the low sensitivity to sub-pixel cloud contamination. The AAI is sensitive to UV-absorbing aerosols and has been used extensively to study two well known types of UV-absorbing aerosols, desert dust (e.g. Chiapello et al., 1999; Alpert and Ganor, 2001; Pandithurai et al., 2001; Spichtinger et al., 2001; Prospero et al., 2002; Colarco et al., 2002; Moulin and Chiapello, 2004) and biomass burning aerosols 10 (e.g. Hsu et al., 1996; Gleason et al., 1998; Hsu et al., 1999a; Goloub and Arino, 2000; Darmenova et al., 2005).

Time series of TOMS data have been used to study seasonal variation of regional aerosol loading. The global distribution and the spatial coverage of UV-absorbing aerosols were demonstrated with time series of TOMS AAI-related residues from 1984 to 1988 (Herman et al., 1997). TOMS AAI data from 1979 to 1993 were converted to aerosol optical depths (AOD), using geographical information on aerosol type and assuming a height for the aerosol layer, and regionally averaged AOD time series showed the seasonal variation of major desert dust and biomass burning areas around the Atlantic Ocean (Torres et al., 2002). Here, time series of regional averaged residues are ented from 1995 to 2000 for a number of climatologically important parts of the globe. Using these time series and other studies, the types of aerosols that are most important for these areas are identified. The influence of the African Monsoon on the aerosol loading over Africa is demonstrated.

Desert dust and biomass burning aerosols have the same effect on the UV radiation by attenuating the Rayleigh reflected radiation below the aerosol layer (e.g. Torres et al., 1998; De Graaf et al., 2005). Desert dust also has a direct effect on the AAI because of its strongly wavelength-dependent imaginary part of refractive index in the UV (Sinyuk et al., 2003; De Graaf et al., 2005). In the wavelength region from 0.4 to $1.0 \mu \mathrm{m}$ the spectral dependence of the absorption coefficients of DDA and BBA is

\section{ACPD}

6, 1321-1353, 2006

\section{GOME temporal and spectral aerosol variation}

M. de Graaf et al.

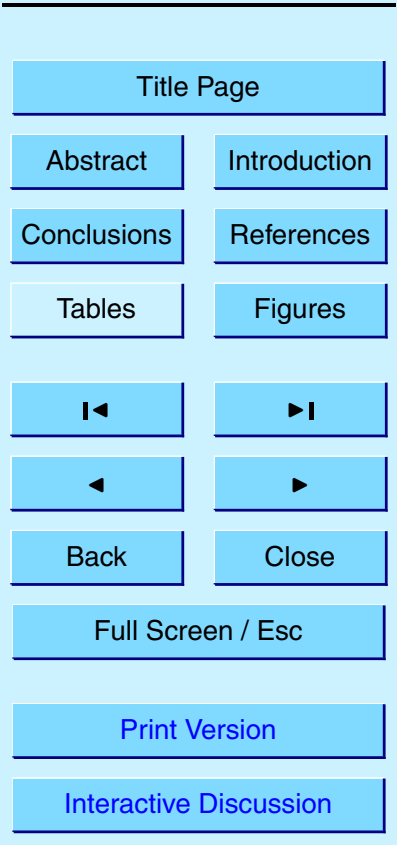

EGU 
different: Biomass burning aerosols with a black carbon (BC) core, obtained with an aircraft over the North Atlantic Ocean, showed a decreasing single scattering albedo with increasing wavelength, while most mineral aerosols have an increasing single scattering albedo with increasing wavelength (Bergstrom et al., 2002). Ground-based 5 (AERONET) data showed a similar spectral distinction between BBA and DDA in the same (440 to $1020 \mathrm{~nm}$ ) spectral region: The single scattering albedo of BBA decreases with wavelength, while the single scattering albedo of DDA increases in the near-UV and becomes constant at longer wavelengths (Dubovik et al., 2002). Here, the effect of these spectral differences on the measured scene is investigated, using empirical 10 data in the spectral range $335-772 \mathrm{~nm}$ of GOME scenes containing known types of UV-absorbing aerosols.

The different GOME products are first described and defined in Sect. 2. Next, in Sect. 3 the time series of regionally averaged GOME residues are presented and used to identify aerosol characteristics in areas that are known to be influenced by UVabsorbing aerosols. In Sect. 4 GOME spectra of reflectances (Sect. 4.1) and residues (Sect. 4.2) at UV to near-IR wavelengths from areas with known types of aerosols are explored to find aerosol specific fingerprints caused by spectrally different absorbing characteristics. An attempt is made to make a distinction between desert dust and biomass burning aerosols (Sect. 4.3), using statistical information of the GOME spec-

\section{Definition of GOME residues}

GOME (Burrows et al., 1999) is a 4-channel grating spectrometer, operating in the wavelength range of $237-794 \mathrm{~nm}$ with a spectral resolution of $0.2-0.4 \mathrm{~nm}$. GOME was launched in April 1995 on board the ERS-2 satellite into a near-polar sun-synchronous orbit at a mean altitude of about $785 \mathrm{~km}$, with a mean local equator crossing time of 10:30 LT. GOME performs nadir observations by scanning the surface from east to west (corresponding to a viewing zenith angle of $-30^{\circ}$ to $+30^{\circ}$ ) in $4.5 \mathrm{~s}$. One across-track

ACPD

$6,1321-1353,2006$

GOME temporal and spectral aerosol variation

M. de Graaf et al.

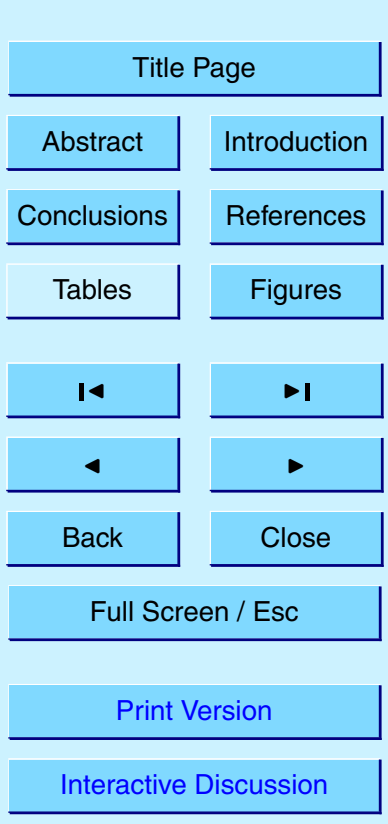

EGU 
scan is divided into three $1.5 \mathrm{~s}$ ground pixels with an average size of $40 \times 320 \mathrm{~km}^{2}$ each. For about $10 \%$ of the time, the swath is reduced to $240 \mathrm{~km}$, and all pixel sizes are four times smaller. Once per day the sun is observed over a diffuser plate for radiometric calibration. A region north of India is never observed, because in this region data from 5 the ERS-2 satellite is downlinked to Earth and during this time no observations can be stored. Since 1999-2000 GOME suffers from serious radiometric degradation in the UV. Therefore, only GOME data from 27 June 1995 to 31 December 2000 were used (De Graaf et al., 2005).

GOME measured reflectances were used to determine residues. The residue $r$ is a wavelength-dependent variable defined as (Herman et al., 1997)

$r_{\lambda, \lambda_{0}}=-100 \cdot\left\{{ }^{10} \log \left(\frac{R_{\lambda}}{R_{\lambda_{0}}}\right)^{\text {meas }}-{ }^{10} \log \left(\frac{R_{\lambda}}{R_{\lambda_{0}}}\right)^{\text {Ray }}\right\}$.

$R_{\lambda}$ is the reflectance at wavelength $\lambda$, defined as $R_{\lambda}=\pi I_{\lambda} / \mu_{0} E_{0}$, with $I_{\lambda}$ the radiance at the top of the atmosphere (TOA) at a wavelength $\lambda, E_{0}$ the solar irradiance at TOA perpendicular to the direction of the incident sunlight and $\mu_{0}$ the cosine of the solar 15 zenith angle $\theta_{0} . R^{\text {meas }}$ is the measured TOA reflectance in a real atmosphere with aerosols and $R^{\text {Ray }}$ the calculated TOA reflectance in an aerosol-free atmosphere with only Rayleigh scattering and absorption by molecules, bounded from below by a Lambertian surface. At the reference wavelength $\lambda_{0}$ a surface albedo $A_{\lambda_{0}}$ is calculated so $R_{\lambda_{0}}^{\text {Ray }}\left(A_{\lambda_{0}}\right)$ is identical $R_{\lambda_{0}}^{\text {meas }}$. Then Eq. (1) can be reduced to$$
r_{\lambda, \lambda_{0}}=-100 \cdot{ }^{10} \log \left(\frac{R_{\lambda}^{\text {meas }}}{R_{\lambda}^{\text {Ray }}\left(A_{\lambda_{0}}\right)}\right) \text {. }
$$

$\lambda$ is the wavelength where the difference between the Rayleigh and the measured scene is calculated. The residue can be calculated for any wavelength pair $\left[\lambda, \lambda_{0}\right]$.
ACPD

$6,1321-1353,2006$

\section{GOME temporal and spectral aerosol variation}

M. de Graaf et al.

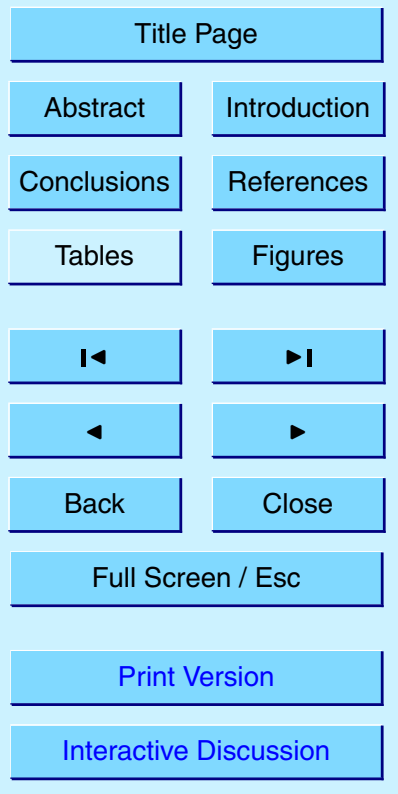

EGU 
Reflectances were determined at eleven wavelengths, namely 335, 380, 416, 440, $463,495,555,610,670,758$, and $772 \mathrm{~nm}$, corresponding to the wavelengths at which the GOME surface albedo database was determined (Koelemeijer et al., 2003). The reflectances were averaged over a one $\mathrm{nm}$ wide wavelength window and pixels with 5 solar zenith angles larger than $80^{\circ}$ were discarded.

Ten spectral residues were determined with reference wavelength $\lambda_{0}=380 \mathrm{~nm}, r_{\lambda, 380}$, for all wavelengths other than $380 \mathrm{~nm}$ listed above $\left(r_{\lambda_{0}, \lambda_{0}}=0\right)$. The reference wavelength can be varied, and the sensitivity of the residue is different at different wavelengths because of the varying Rayleigh reflectance, which can be very strong in the UV. More10 over, the relationship between $r_{\lambda, \lambda_{0}}$ and $r_{\lambda_{0}, \lambda}$ can be nonlinear (De Graaf and Stammes, 2005). But for reference wavelengths in the visible and IR the high surface albedo over land completely dominates the residue. So of the 55 possible wavelength combinations per pixel (no extra information is added with a change of $\left[\lambda, \lambda_{0}\right] \rightarrow\left[\lambda_{0}, \lambda\right]$ ) only the ten residues with $\lambda_{0}=380 \mathrm{~nm}$ were retained, because $380 \mathrm{~nm}$ is the wavelength traditionally used for the AAI and in the UV the surface albedo is dark over both land and oceans.

The AAl is defined as the positive residue determined at $\left[\lambda, \lambda_{0}\right]=[335,380] \mathrm{nm}$, $r_{335,380}>0$. In general, all pixels with a residue greater than zero are indicative for UVabsorbing aerosols in the scenes (Hsu et al., 1996; Torres et al., 1998; De Graaf et al., 2005). In this paper a threshold of 0.5 is used to select scenes with UV-absorbing 20 aerosols. Negative residues also contains geophysical information, as is shown in this paper. Negative values generally indicate clouds or scenes free of UV-absorbing aerosols, but these have never yet been investigated.

Between 1995 and 2000 the global monthly averaged residue varied sinusoidally around a mean of -1.2 with an amplitude of 0.13 and a phase shift of 8.0 months. The possibility of a solar zenith angle error for this sinusoidal variation was ruled out, and the sine was removed as it was believed to be the result of an error in the characterisation of the Bi-directional Scattering Distribution Function (BSDF) of the solar diffuser plate of GOME. After 1998 an exponential decrease in the residue was found of about -4 in two years, due to degradation of the UV-channels of GOME which was stronger at

ACPD

$6,1321-1353,2006$

\section{GOME temporal and spectral aerosol variation}

M. de Graaf et al.

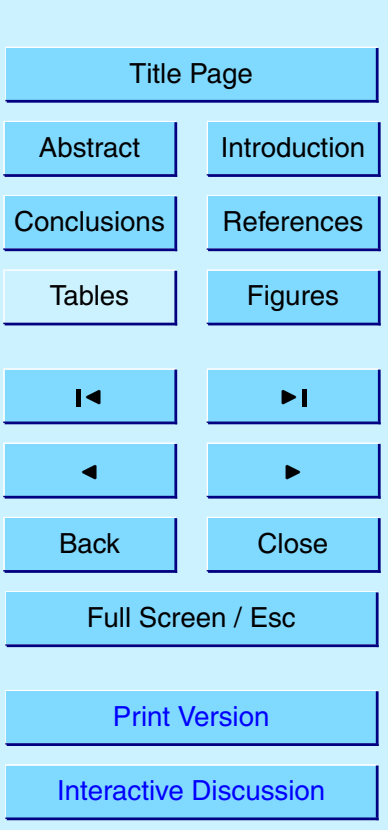

EGU 
$335 \mathrm{~nm}$ than at $380 \mathrm{~nm}$. This was also corrected. The corrections in the last two months of the data set, November and December 2000, were rather large and the data of these months should be treated with caution. (See De Graaf et al., 2005, for more details on the data calibration.) The resultant global mean residue was -1.2 with a variation in 5 the monthly average of less than 0.25 .

\section{Temporal behaviour of UV-absorbing aerosols from GOME}

\subsection{GOME regionally averaged residue time series}

Fifteen areas on the globe were selected to study the local time series and trend of the GOME residue $r_{335,380}$ in that area (see Fig. 1), 1: northwest Africa (red); 2 : North 10 Atlantic Ocean (magenta); 3: southwest Africa (green); 4: South Atlantic Ocean (cyan); 5: Sahel (khaki); 6: Indonesia (dark green); 7: northern South America (light green); 8: western Europe (blue); 9: Australia (yellow); 10: Saudi Arabia (brown); 11: India (grey); 12: Gobi Desert (orange); 13: Hong Kong (purple); 14: Alaska (blue grey); 15: western North America (brick red). The GOME residue $r_{335,380}$ was averaged 15 over each of these areas daily from July 1995-December 2000 (Fig. 2), to show the characteristic long-term time series of phenomena related to aerosols and clouds in these particular areas. Residues of all pixels in the areas were averaged, not only residues larger than zero or 0.5. Averages of AAI are also possible, but because the AAI is only defined from zero upwards, averages of AAls are hard to interpret. Since cloudy and aerosol-free pixels give negative values, the average residue of an area will usually be negative. UV-absorbing aerosol events will raise the average, but not necessarily to positive values. The global daily residue was also determined.

Over northwest Africa and the North Atlantic Ocean very high residues can be found, caused by frequent desert dust blowing events. These desert dust plumes often extend Sahara (e.g. Prospero et al., 2002; Reid et al., 2003; Kaufman et al., 2005), therefore

ACPD

$6,1321-1353,2006$

GOME temporal and spectral aerosol variation

M. de Graaf et al.

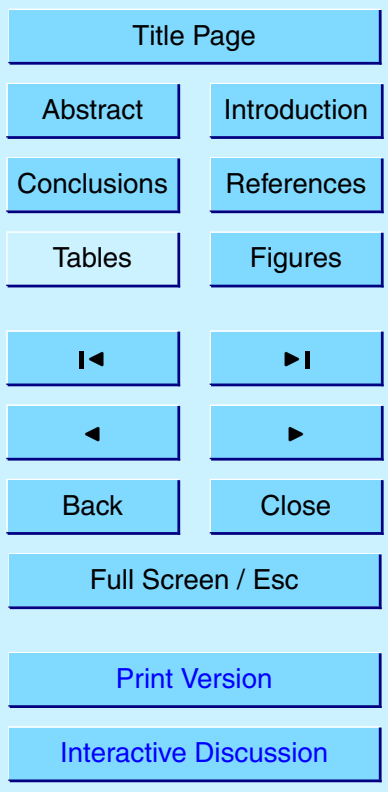

EGU 
the two curves are highly correlated. The curves show a high seasonal variation, the residue peaking in the boreal summer months due to increased wind speeds when the sun is higher overhead. A similar seasonal variation was found in these areas between 1979 and 1993 using TOMS AOD (Torres et al., 2002). The aerosol loadings over the 5 Sahara were highest in May-July over the Sahara and in July over the Atlantic Ocean between 1979 and 1993. No such time lag exists between these areas in 1995-2000.

Over southwest Africa a very clear seasonal variation can also be observed, with high residues in the austral spring. These high residues are caused by anthropogenic biomass burning in the dry period, while the low residues are caused by the monsoon 10 rains, see below. The biomass burning aerosol plumes extend over the South Atlantic Ocean, and the residue over the South Atlantic correlates well with the residue over southwest Africa. Both signals show a secondary maximum in the austral summer, which is caused by aerosols just north of the equator being blown south. The same secondary maxima were also found in TOMS AAI data in areas south of the equator 15 (Herman et al., 1997; Torres et al., 2002). The region just north of the equator, the Sahel, shows a very strong seasonal variation which peaks in the dry season. In the Sahel biomass burning aerosols and desert dust are often found together in the dry season and it is not clear which aerosols cause the strong maxima. The central African regions are treated in more detail in Sect. 3.2.

In Indonesia forest fires are very common during dry periods, but there are usually many single fires scattered throughout the selected region, which cannot be seen in the regional average, so a seasonal variation is not visible in Fig. 2. However, from September 1997 till November 1997 severe biomass burning events caused huge persistent forest fires in Borneo and other parts of Indonesia in the El-Niño year 1997 (Duncan et al., 2003), causing high AAls in this area (De Graaf et al., 2005). These events were so severe that they cause a solitary peak in the regional averaged residue over Indonesia in the fall of 1997.

High residues are observed over northern South America in boreal autumn almost every year, which is caused by biomass burning of the tropical forests. The strong

ACPD

6, 1321-1353, 2006

GOME temporal and spectral aerosol variation

M. de Graaf et al.

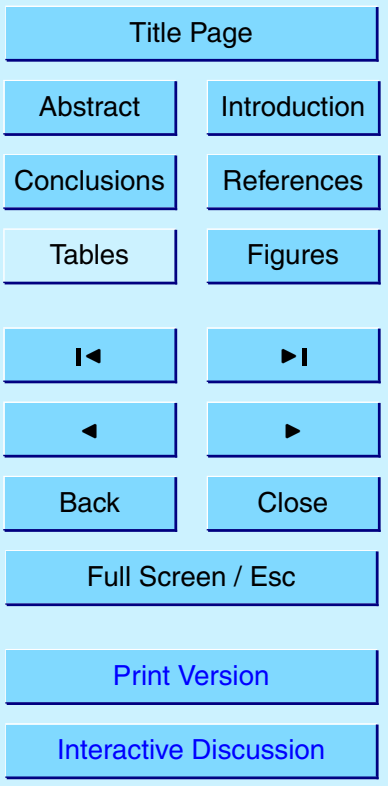

EGU 
seasonal variability is consistent with SCAR-B observations, which showed fire activity peaks in late August and September in 1995 (Kaufman et al., 1998), and TOMS AAI, which showed peak values in August and September from 1979 to 1993 (Torres et al., 2002).

5 Over Europe, very few UV-absorbing aerosols are observed by GOME, therefore the overall residue is low year-round. A clear seasonal signal is observed, caused by cloud cover changes over Europe, where in boreal winter cloud cover is about twice that in boreal summer, reducing the residue in the winter. This example shows that also geophysical parameters other than UV-absorbing aerosols, namely clouds, have a strong and consistent effect on the residue.

Over Australia no clear pattern is visible. Although in this area desert dust and biomass burning events are common, these events are irregular in space and time and the area-averaging smooths out the events. The northern part of Australia, where biomass burning events are most common (e.g. Tanré et al., 2001), has been excluded 15 in the present analysis, because this area has the same characteristics as Indonesia.

The Saudi Arabian peninsula shows high residues and distinct seasonalities, correlating well with the signal in northern Africa. The signal over Saudi Arabia is smaller than over northern Africa, but the seasonalities match, because both are caused by desert dust changes driven by the same seasonal variation of the sun over both areas.

Over India residues are highest in spring and lowest in autumn. The source of UVabsorbing aerosols is biomass burning from urban and industrial areas. This pollution reaches its maximum at the end of the hot dry season. The monsoon rains set in in May in the south and in June in the North, lowering the temperatures and washing the aerosols from the atmosphere. After the period of the retreating monsoon, from September in the north to December in the south, the aerosol loading is gradually increased again.

Over the Gobi Desert a strong seasonality can again be observed, with high peaks in the boreal winter, which is its dry period. The source of the high residues over the Gobi Desert is of course desert dust (e.g. Prospero et al., 2002; Darmenova et al.,
ACPD

$6,1321-1353,2006$

GOME temporal and spectral aerosol variation

M. de Graaf et al.

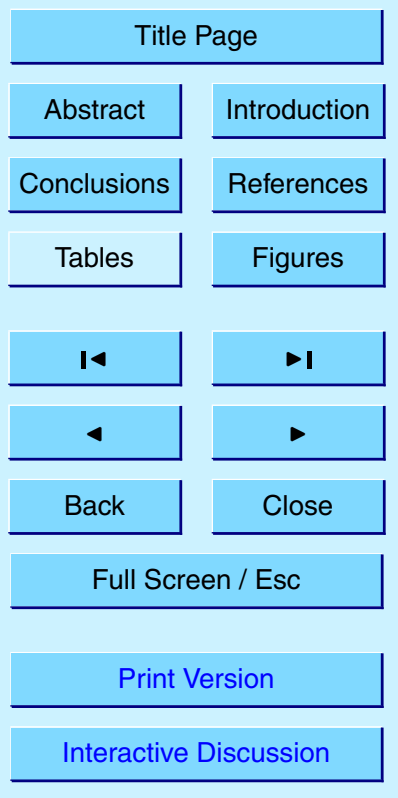

EGU 
2005; Kim et al., 2005).

The same strong seasonal variation can be observed over Hong Kong as well. Pollution by industrial aerosols often infest this area (Tanré et al., 2001), however, the high correlation between the residue signal from the Gobi Desert and that from the Hong

5 Kong area suggests a connection between the origin of the high residues over both areas (which is desert dust for the Gobi desert).

Over Alaska, western Canada and the north Pacific a seasonal variability with high residues in the boreal winter can be observed. Although this area must be treated with care in view of the large solar zenith angles in winter, biomass burning aerosols from 10 forest wildfires are not uncommon here.

The west coast of North America shows a rather constant signal of negative averaged residues, although occasional outbreaks of forest fires and desert dust events cause locally high residues. But these are irregular and smoothed out in the average.

The global mean residue between 1995 and 2000 is -1.2 , with a small decreasing 15 trend of -0.029 per year. The trend is probably due to degradation of the sensors; a residue difference of 0.029 amounts to a reflectance error of less than $0.07 \%$. The global mean residue does not show any seasonal variation in Fig. 2, because a sine with a period of one year (amplitude 0.13 and phase shift of 8.0 months) was filtered out of the data, since it was believed to be a calibration error (see Sect. 2). In view of the above discussions, a sinusoidal seasonal variation in the global mean residue could also have a geophysical cause.

\subsection{GOME residue - African Monsoon relationship}

The GOME residue $r_{335,380}$ of the shaded area in Fig. $1\left(30^{\circ} \mathrm{S}-30^{\circ} \mathrm{N}, 0^{\circ}-20^{\circ} \mathrm{E}\right)$, which is an area that is strongly influenced by the African monsoon (both West and East 25 African Monsoon (e.g. Webster, 1987; Janicot et al., 1998; McGregor and Niewold, 1998)), was averaged zonally. The time series from July 1995 to December 2000 of this zonally averaged residue is plotted in Fig. 3a. During the dry period in Africa, desert dust storms and biomass burning events cause high residues, indicated by red pixels.

\section{GOME temporal and spectral aerosol variation}

M. de Graaf et al.

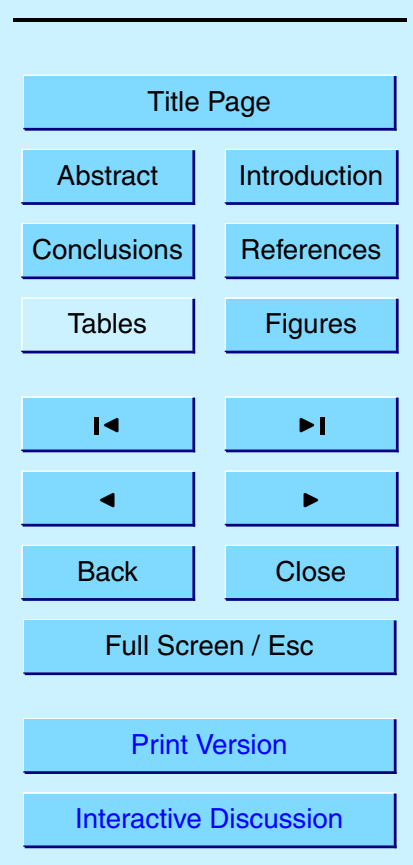

EGU 
Outside the dry months the monsoon rains prevent the existence of dust storms, fires and aerosol plumes. The atmosphere is cloudy and washed clean, yielding negative residues. As the InterTropical Convergence Zone (ITCZ) and monsoon rains shift with the seasons the negative residues travel along with it, causing the sinusoidal violet-blue 5 path through Fig. $3 a$.

In the north, located over the Sahara, GOME residues are high year-round. North of $20^{\circ} \mathrm{N}$ the GOME residue peaks in the boreal summer months, in accordance with the time series in Fig. 2. A small area centred around $17^{\circ} \mathrm{N}$ has very high GOME residues year-round for all the years shown. This coincides with the Bodélé depression, an area 10 centred around $17^{\circ} \mathrm{N}, 18^{\circ} \mathrm{E}$, which is known to be an enormous source of desert dust aerosols (Prospero et al., 2002).

North of the equator, between $0^{\circ}$ and $10^{\circ} \mathrm{N}$ the GOME residues alternate between high, positive values in the boreal winter months and negative values in the boreal summer months. The high values in winter have two possible origins: biomass burn15 ing aerosols from the vegetated Sahel region or desert dust blown in from the Sahara, north of this area. The local aerosol peaks centred around $5^{\circ} \mathrm{N}$ seem to be disconnected from the desert dust peaks at about $18^{\circ} \mathrm{N}$, but mixing with desert dust transported from the north cannot be ruled out. The GOME residue cannot be used to distinguish between these types, but most likely both types of aerosols can be present in the Sahel area, depending on the prevailing wind directions.

Between $0^{\circ}$ and $10^{\circ} \mathrm{S}$ the picture is a bit more complicated. The aerosols in the primary maxima in boreal summer to autumn are local biomass burning aerosols from vegetation fires. The time series of southwest Africa (Fig. 2) also showed secondary maxima in boreal winter, which were also found in TOMS residues in a box just south of the equator in Africa between 1984 and 1988 (Herman et al., 1997) and less clearly in TOMS AOD from 1978 to 1993 (Torres et al., 2002), because in the latter only data from $5^{\circ}-25^{\circ} \mathrm{S}$ was used. These secondary maxima were attributed to excursions of smoke aerosols from events just north of the equator to the south by the prevailing winds. Figure 3 a confirms these excursions of aerosols from north of the equator to
ACPD

$6,1321-1353,2006$

GOME temporal and spectral aerosol variation

M. de Graaf et al.

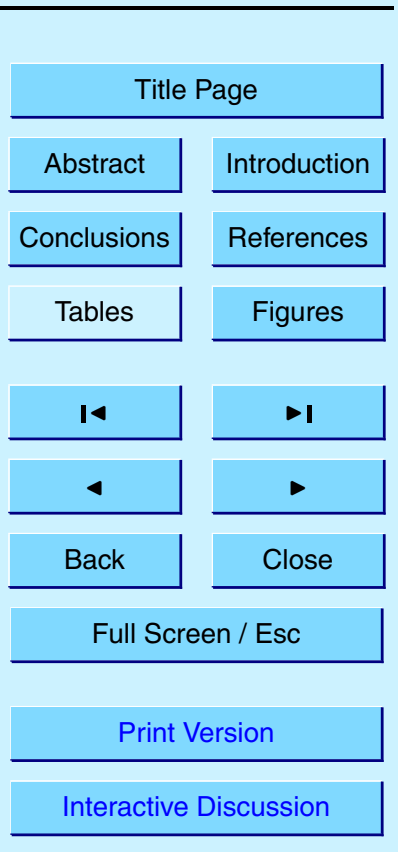

EGU 
the south. However, since the types of aerosols north of the equator are uncertain, the biomass burning aerosols in these secondary maxima can also be mixed with desert dust.

Below about $10^{\circ} \mathrm{S}$ the GOME residue alternates between high values in boreal sum5 mer and autumn and low values in boreal winter, out of phase with residues just north of the equator. The high residues are caused by persistent local vegetation fires occurring every year in and around Angola in the dry period. These fires are mainly man-made to benefit agriculture.

To check the relationship between negative GOME residues and monsoon rains, the 10 precipitation in the shaded area of Fig. 1 was also averaged zonally (Fig. 3b). The data used for this figure were precipitation observations gridded to a one by one degree grid, obtained from Deutscher Wetterdienst (http://gpcc.dwd.de). Although precipitation data are usually very irregular, the data in Fig. 3b correlate very well with the GOME residue, even when the GOME residues were plotted for each day that the data were available, while the precipitation data were monthly averaged.

Figure 3 shows the asymmetry of the African monsoon: In the north there is a clear boundary of the monsoon at about $15^{\circ} \mathrm{N}$, visible in both the GOME residues and the precipitation data. In the south the monsoon boundary is not very clearly defined and the monsoon travels farther south than north. The well defined northern boundary is caused by dry, hot winds blowing from the north, known as the Harmattan. This hot dry continental air is less dense than the cool moist south-westerly monsoonal flow and is uplifted, suppressing local precipitation (e.g. McGregor and Niewold, 1998), and hence suppressing negative residues. Because the ITCZ travels farther south than north and since aerosol plumes will probably not cross the ITCZ, the aerosol plumes originating north of the equator are able to cross the equator, while the aerosol plumes originating south of the equator are mainly confined to the south.
ACPD

$6,1321-1353,2006$

\section{GOME temporal and spectral aerosol variation}

M. de Graaf et al.

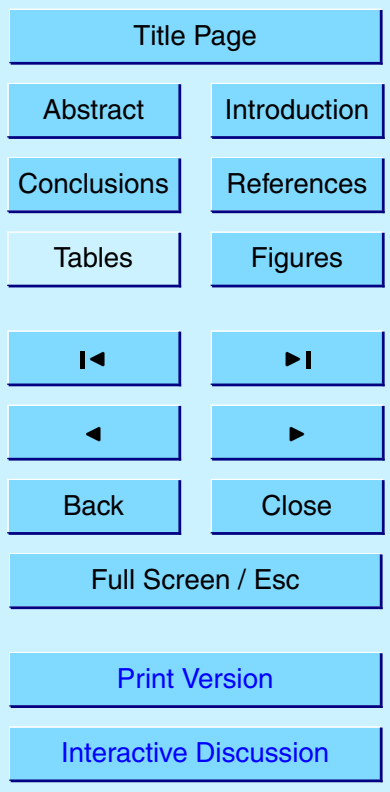

EGU 


\section{Spectral behaviour of UV-absorbing aerosols from GOME}

In this section GOME spectra of biomass burning aerosol scenes and desert dust aerosol scenes are explored to examine the effect of their spectrally different absorption coefficients on the measured scene. The investigation is restricted to a statistical 5 survey of GOME spectra in four areas, numbers 1-4 in Fig. 1, which are assumed to be typical for the occurrence of BBA and DDA types, both over land and ocean.

\subsection{Reflectance spectra}

All measured GOME reflectance spectra of scenes containing UV-absorbing aerosols from June 1997 until August 1997 were averaged for each of the four areas (see Fig. 4).

10 Scenes with UV-absorbing aerosols were selected choosing only those with an AAI greater than 0.5. The number of UV-absorbing GOME scenes between June and August 1997 in northwest Africa was about 20000, over the North Atlantic Ocean about 10000 , in southwest Africa about 3500 and over the South Atlantic Ocean about 4000. In grey-scale a contour plot is given of the histogram of all spectra in the three months, 15 indicating the range of the spectra, while the solid line is the averaged spectrum. The dashed line shows the surface albedo spectrum of the areas averaged over the months June to August. These were determined from GOME minimal reflectances in the years 1995 to 2000 for each month (Koelemeijer et al., 2003).

Over northwest Africa (left upper panel in Fig. 4) the reflectances of the (mineral) 20 aerosol laden scenes decrease with increasing wavelength in the UV, and increase
with increasing wavelength in the visible and near-IR. In the visible and near-IR the
desert surface is very bright and the reflectance is increasingly dominated by the surface albedo. Only below about $500 \mathrm{~nm}$ is the desert surface dark enough that the atmospheric component can be distinguished from it.

25 Over the North Atlantic Ocean (left lower panel) the surface albedo is low in the UV, and even lower in the visible and the near-IR. Thus, the behaviour of the reflectance is primarily due to atmospheric effects. The reflectances of the desert dust aerosol
ACPD

6, 1321-1353, 2006

GOME temporal and spectral aerosol variation

M. de Graaf et al.

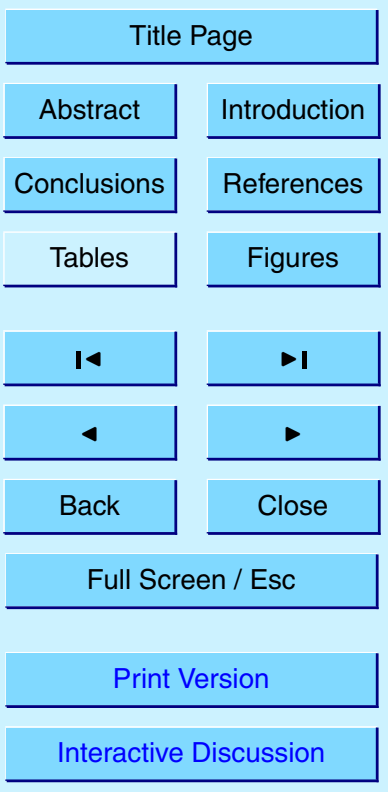

EGU 
scenes over the ocean decrease with increasing wavelength over the entire spectral region.

Over southwest Africa (right upper panel) the reflectances of the (biomass burning) aerosol laden scenes decrease with increasing wavelength until about $650 \mathrm{~nm}$, after 5 that the reflectances start to increase with increasing wavelength. This is because vegetation is dark until about $650 \mathrm{~nm}$, after that it rapidly becomes brighter with increasing wavelength. In addition, BBA have a black carbon core which is highly absorbing and, although the BBA scene spectra over land have a large spread, on average the reflectance is low.

10 Over the South Atlantic Ocean (right lower panel) the surface is again dark at all wavelengths, and the average reflectance is almost constant with wavelength. The average reflectance of the BBA scenes over the ocean is much higher than over land, and also the spread is larger.

The spectral behaviour of BBA over ocean is distinctly different from that over land, 15 because BBA is chemically very active and highly hygroscopic, and its internal chemical and physical properties change quickly during the first few hours to days after its creation. The cores of fresh biomass burning aerosols are made up of black carbon and other substances, depending on the source (e.g. combustion and fuel type). Fresh biomass burning aerosols are known to burn away clouds due to the semi-direct effect 20 (Hansen et al., 1997; Ackerman et al., 2000): The black carbon cores of the aerosols absorb solar radiation and heat the atmosphere locally, inhibiting cloud growth. Therefore, clouds and biomass burning aerosols are rarely found together near fires (Koren et al., 2004). As the BBA age and move away from the source the aerosols are coated with water, and the aerosols become very efficient cloud condensation nuclei (CCN). 25 Therefore, scenes with aged BBA are often cloud contaminated. Clouds yield high, gray reflectances, and polluted clouds also yield high residues. The relative importance of these competing properties of BBA change over time, which is expressed by the different spectra over land and ocean. Over land BBA scene spectra are on average lower than those over oceans, because over oceans biomass burning aerosols
ACPD

$6,1321-1353,2006$

\section{GOME temporal and spectral aerosol variation}

M. de Graaf et al.

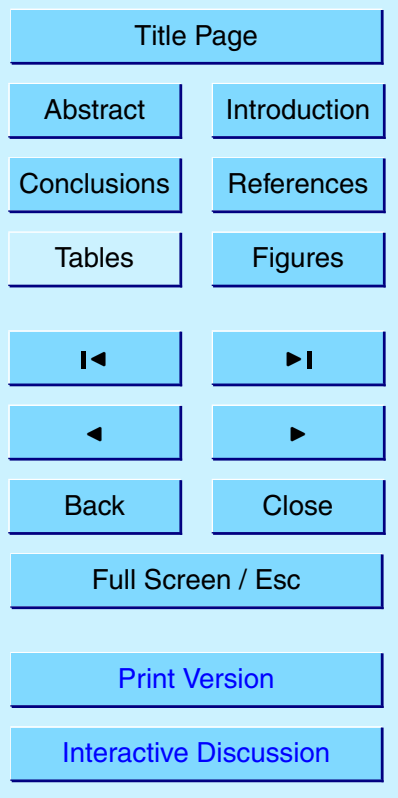

EGU 
are by definition aged aerosols well away from the source. The most important effect of the high variability of BBA properties however, is the large spread of the BBA scene spectra, which is also larger over ocean than over land.

DDA can usually be found in warm dry desert air, where clouds are created less 5 easily. Mineral aerosols are also chemically more inert and less hygroscopic, so clouds are not easily formed in desert dust aerosol plumes. Therefore the spectra of DDA scenes are more uniform than the BBA spectra.

\subsection{Residue spectra}

As a next step, the spectral behaviour of the residue with reference wavelength $380 \mathrm{~nm}$, ${ }_{10} r_{\lambda, 380}$, was investigated for all the scenes containing UV-absorbing aerosols in the areas 1-4 between June and August 1997 (see Fig. 5). The residues at the lowest wavelength, $r_{335,380}$, are positive (and higher than 0.5 ) for all areas, because this criterion was used to select UV-absorbing aerosol scenes. In Fig. 5 the grey-scale contour plot indicates the range of the observed residues and the solid line is the average of all 5 residues in the three months.

Over northwest Africa (left upper panel of Fig. 5) the residue rapidly decreases with increasing wavelength, because the surface reflectivity increases with increasing wavelength (cf. Fig. 4). Furthermore, Rayleigh scattering decreases with increasing wavelength so that the bright desert surface dominates the signal.

20 Over southwest Africa (right upper panel) the residue slightly decreases with increasing wavelength until about $700 \mathrm{~nm}$, above which the vegetation surface reflectivity starts dominating the residue, sharply decreasing it.

Over the North Atlantic Ocean (left lower panel) the surface reflectivity is low for all wavelengths given and again atmospheric effects dominate. For desert dust laden scenes the residue decreases slightly until about $450 \mathrm{~nm}$, after which it increases again and becomes almost zero, but the spread becomes large at longer wavelengths. Desert dust is absorbing in the UV, but as the Rayleigh effect becomes negligible at longer wavelengths any effect can influence the sensitive residue there. On average

ACPD

$6,1321-1353,2006$

GOME temporal and spectral aerosol variation

M. de Graaf et al.

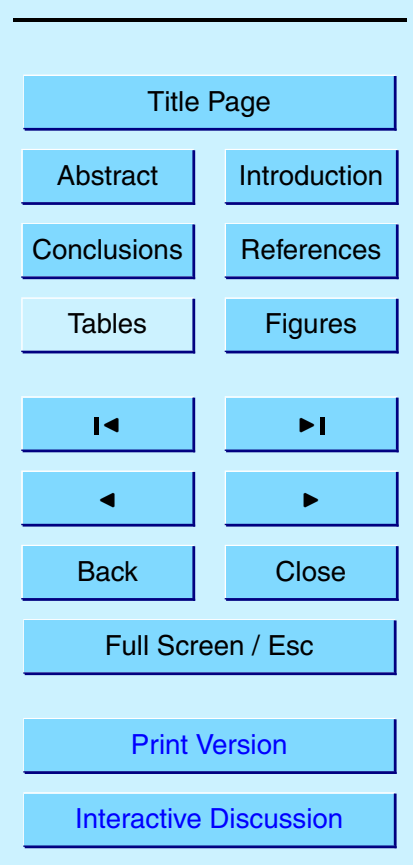

EGU 
the desert dust aerosols seem to have no effect on the slope of the residue spectrum.

Over the South Atlantic Ocean (lower right panel) the residue is on average continuously decreasing, but only very slightly. The spread of scene residues is comparable for BBA and DDA scenes. At longer wavelengths the spectral behaviour of the single 5 scattering albedo of BBA is different from that of DDA but apparently the effect is too small to be noticeable using a residue, due to the low Rayleigh reflectance at longer wavelengths. Therefore other effects, like clouds and surface albedo, dominate.

The effect of the surface albedo on the residue beyond the UV is strongly increased due to the strongly reduced Rayleigh optical thickness at longer wavelengths, and can 10 be clearly observed in Figs. $5 a$ and b. Furthermore, in the UV a spectrally independent (gray) surface albedo is a good assumption for the four areas (cf. Fig. 4), but at longer wavelengths the surface albedo is clearly wavelength dependent. To correct the residue for this effect, i.e. subtracting the contribution of the varying surface albedo, would imply the knowledge of a cloud fraction for each scene. The scene TOA re15 flectance of the cloud-free part of a pixel could be simulated using the pixel's ground albedo and radiative transfer calculations for a Rayleigh atmosphere. The cloudy part of a scene on the other hand, has a more or less wavelength independent scene albedo, which would not affect the residue calculations. So a correction scheme would imply a good cloud fraction retrieval for GOME pixels and radiative transfer calculations for the cloud-free part of the pixels. Since GOME cloud fraction retrievals are not very accurate, this was not attempted. Indeed, the strong point of the UV residue method is the simplicity of the algorithm and its insensitivity to sub-pixel cloud contamination, which makes it so useful for wide-view sensors.

\subsection{Selection criteria}

25 From Fig. 5 it might be concluded that over land DDA may be separated from BBA using the residue $r_{\lambda, 380}$ at short visible wavelengths, e.g. $\lambda=440 \mathrm{~nm}$. Similarly, from Fig. 4 it might be concluded that over the oceans DDA may be separated from BBA using the absolute reflectance $R$ at e.g. $380 \mathrm{~nm}$. To test this, in Fig. 6 four scatter diagrams are
ACPD

$6,1321-1353,2006$

\section{GOME temporal and spectral aerosol variation}

M. de Graaf et al.

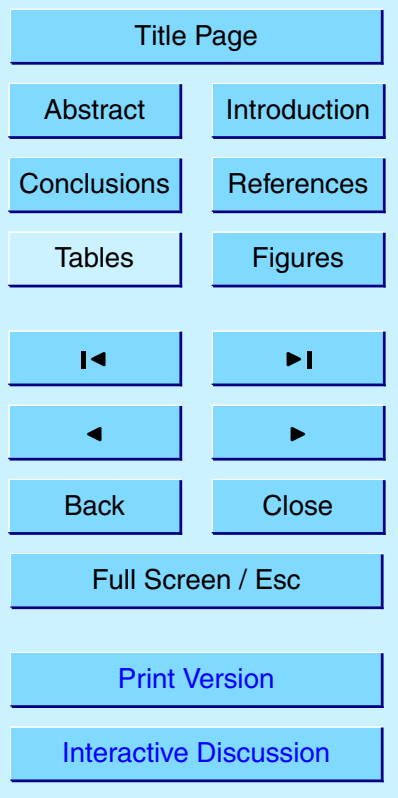

EGU 
presented of the residue $r_{440,380}$ versus the reflectance $R_{380}$ of the GOME scenes in areas 1-4 in Fig. 1 with AAI >0.5 between June and August 1997.

Over land $98 \%$ of the scenes from northwest Africa have an $r_{440,380}$ lower than ACPD -5 , while $97 \%$ of the scenes from southwest Africa have an $r_{440,380}$ higher than -5 .

5 The difference between the two sets of points could be increased using $r_{\lambda, 380}$ with a wavelength $\lambda$ higher than $440 \mathrm{~nm}$ (see Fig. 5), but this difference would be mainly caused by the surface albedo. Therefore, a selection criterion for scenes over land was defined as: All scenes with AAI $>0.5$ and $r_{440,380}<-5$ are DDA scenes (lying in the brown box in Fig. 6) and all scenes with AAI $>0.5$ and $r_{440,380}>-5$ are BBA scenes 10 (lying in the dark blue box).

Over ocean DDA scenes with an AAI $>0.5$ have on average a lower absolute reflectance than BBA scenes. $98 \%$ of the scenes over the North Atlantic Ocean have a reflectance $r_{380}$ lower than 0.4 . However, the reflectance of BBA scenes is very variable: the reflectances of scenes from the South Atlantic Ocean vary from 0.2 to about 150.7 and only $52 \%$ of the selected scenes have a reflectance higher than 0.4 . This large spread of reflectances can also be observed in Fig. 4 and is probably caused by the large spread in occurrence of polluted clouds. Still, a selection criterion for scenes over the oceans was defined as: All scenes with AAI $>0.5$ and $R_{380}<0.4$ are DDA scenes (lying in the orange box in Fig. 6) and all scenes with AAI $>0.5$ and $R_{380}>0.4$ are BBA 20 scenes (lying in the light blue box).

The selection criteria were applied to data from June to August 1997 (Fig. 7a) and November 1997 to January 1998 (Fig. 7b). The first period is the same period for which the selection criteria were determined, so the results in Africa are predictable, but it shows the results for the entire globe. The second period shows the result for 25 the entire globe in a different season. All the GOME scenes with absorbing aerosols $(A A I>0.5)$ in the indicated periods are plotted, except sunglint scenes (see below). All land DDA scenes are plotted in brown, all land BBA scenes are plotted in dark blue, all ocean DDA scenes are plotted in orange, and all ocean BBA scenes are plotted in light blue.

6, 1321-1353, 2006

\section{GOME temporal and spectral aerosol variation}

M. de Graaf et al.

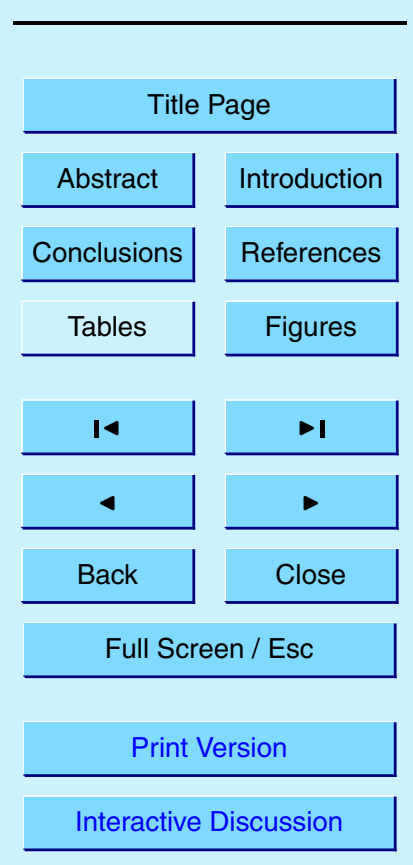

EGU 
In Fig. 7a, over north Africa in boreal summer $98 \%$ of the desert dust pixels over land are plotted in brown and over the North Atlantic $98 \%$ of desert dust aerosols extending over the oceans can be observed as a plume of orange pixels. The expected two percent of blue pixels are scattered through the region without a clear pattern. In 5 southern Africa in boreal summer almost all biomass burning aerosols over land are plotted in dark blue, the three percent of erroneous brown pixels also do not seem to have a pattern. Over the South Atlantic Ocean west of Africa about half of the pixels are plotted in light blue and half of the pixels are plotted in orange. There is no clear separation of light blue and orange pixels, in particular the orange pixels are not found 10 closer to the coast than light blue pixels, rather the contrary. This configuration might be expected if the increase in reflectance (causing the blue-orange colour difference) resulted from an increasing amount of clouds formed by ageing aerosols acting as increasingly effective cloud condensation nuclei.

Over land, outside Africa, in the boreal summer months the results are not unsatis15 factory (Fig. 7a). In the Middle East region the pixels are correctly marked brown where DDA are expected. In western North America the majority of the land pixels are brown, although both DDA and BBA are common here. Over the Himalayas most pixels are also brown, but high AAls over high mountainous areas must be treated with caution, because the resolution of the topography database used to determine the residue is insufficient (De Graaf et al., 2005). The same holds for the Andes. The rest of South America is mainly blue, correctly indicating BBA, which is also true for southern Africa, Indonesia and Australia.

In the winter months (Fig. 7b) the results are not so good. Over the Sahel region, central Africa, a large brown area borders a small elongated blue area. In view of the discussion of Fig. 3, this is not necessarily erroneous: in boreal winter aerosol plumes from the north travel south and it is not impossible that these aerosols are desert dust from the Sahara, bordered on the south by local BBA. However, the distinct land-sea difference of orange sea pixels and blue adjacent land pixels indicates a problem in either one or both selection criteria.
ACPD

6, 1321-1353, 2006

\section{GOME temporal and spectral aerosol variation}

M. de Graaf et al.

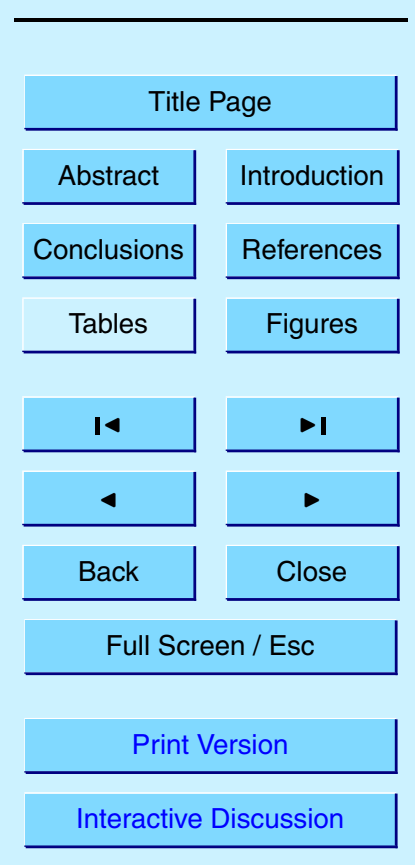

EGU 
In central Australia a region is brown in both seasons, indicating desert dust, which is probably caused by specific surface conditions. In Indonesia land pixels are still blue, which is a good result and in Asia pixels are brown near desert areas and blue nearer to the coast. This is an interesting result. BBA are very common in China and east

5 Asia and recent evidence suggests a blackening of DDA due to mixing with soot particles produced over the industrial/urban areas of China, as DDA moves from the central Asian desert areas to the eastern coastal areas, changing the spectral characteristics of the mineral aerosols (Kim et al., 2005). A spectral change of microphysical properties might induce a change of spectral residue. However, in general the results over 10 land will be determined by the surface reflectance.

Over the oceans, stripes of orange pixels can be observed over the Pacific and the Atlantic in both boreal summer and winter. In the winter the stripes are shifted to the southern hemisphere to where the sun is overhead. These pixels were assumed to be caused by sunglint, since sunglint causes high AAls and they are expected in this region (De Graaf and Stammes, 2005) and GOME AAI pixels were not initially corrected for sunglint. However, to exclude sunglint all east pixels where sunglint could be present have been removed and can thus not explain the orange pixels.

South of Alaska in boreal winter about half of the UV-absorbing pixels are marked blue, indicating BBA, half are orange, indicating DDA. Any absorbing aerosols in this area are caused by biomass burning, but the large spread of reflectances of BBA scenes makes an accurate distinction between DDA and BBA impossible. Orange pixels are ambiguous, but according to the analysis of African summer aerosol scenes, light blue pixels indicate BBA. So the pixels east of Asia over the Pacific in boreal winter are BBA.

\section{Conclusion}

GOME $r_{335,380}$ residue data are useful to study multi-year time series and trends of phenomena connected to aerosols and clouds globally or in a certain area. They can
ACPD

6, 1321-1353, 2006

\section{GOME temporal and spectral aerosol variation}

M. de Graaf et al.

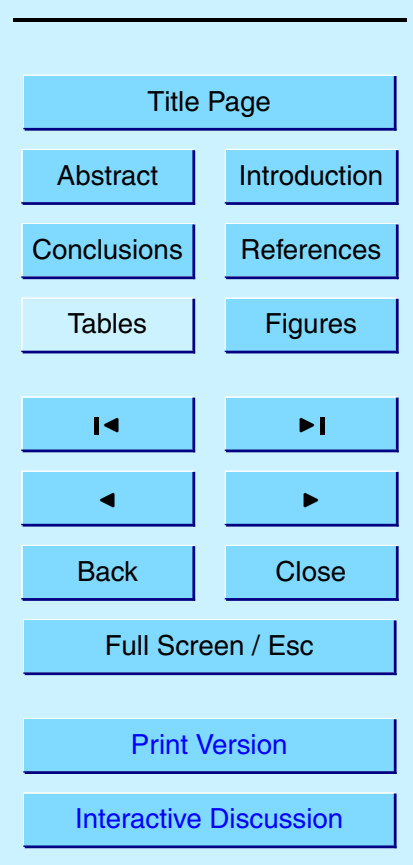

EGU 
be used to monitor seasonal cycles or individual aerosol events. For example, the seasonal variation of the residue over western Europe can be related to the seasonal variation of cloud cover, and the exceptionally large amount of biomass burning events in Indonesia in 1997, caused by El Niño, was illustrated with a regionally averaged 5 residue. The seasonal variation of desert dust and biomass burning events in Africa was shown to be related to the African monsoon.

In northern Africa near the Sahara and over the adjacent North Atlantic Ocean desert dust is very common and can be found year-round. In southwest Africa biomass burning events occur regularly in the dry season. These areas were chosen to study the 10 spectra of aerosol laden scenes in order to find spectral fingerprints of different aerosol types.

Dust storms are most severe in the boreal summer in northern Africa, when the sun is overhead and wind speeds are peaking. This can be observed in the residue, which has a clear seasonal variation, peaking in the boreal summer. In boreal winter the dust storms are less severe and frequent but are still among the most intense on the globe. The surface albedo in the visible and near-IR is very high over deserts, therefore UV methods are necessary to study desert dust aerosols. The reflectance spectra of desert dust scenes over land decrease with increasing wavelength in the UV and increase with increasing wavelength in the visible and near-IR due to the increasing surface albedo. Over the oceans the surface albedo is low, and the absolute reflectance of desert dust scenes is low at all wavelengths and decreasing with increasing wavelength. Desert dust aerosols are chemically inert and have a low hygroscopicity, therefore the spectra of desert dust scenes have a small spread and desert dust can be classified spectrally as one type.

25 Biomass burning aerosols are common in the austral spring over southwest Africa and the adjacent South Atlantic Ocean, which is the local dry season. In the wet season no fires and no aerosols are found in this area. The average spectral behaviour of biomass burning scenes is slightly decreasing with increasing wavelength in the UV and visible and slightly increasing with increasing wavelength in the near-IR, due to the

ACPD

$6,1321-1353,2006$

GOME temporal and spectral aerosol variation

M. de Graaf et al.

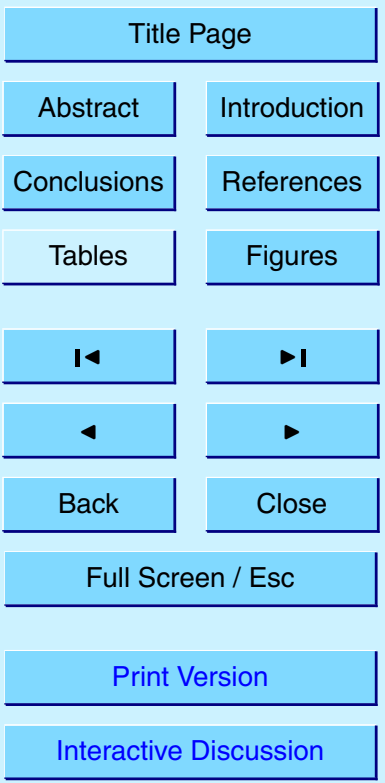

EGU 
increasing reflectance of vegetation in this spectral range. Biomass burning aerosols are highly variable in chemical and physical properties, depending on fuel type and age of the aerosols. As a result, the variation of the biomass burning aerosol scenes spectra is very large. Over oceans this effect is even more pronounced, as biomass 5 burning aerosols over oceans are by definition aged aerosols, having their origin over land. This is expressed in the spectra of biomass burning aerosols over oceans, which have the largest spread of spectra presented in this paper. The high variability of biomass burning aerosol properties makes it hard to classify biomass burning aerosols spectrally as one distinct type.

10 The residue method for the detection of UV-absorbing aerosols is suitable for application over both land and oceans. An attempt was made to extend the method using residues at longer wavelengths, i.e. in the visible and the near-IR. However, due to the high surface albedo over land, especially over deserts, and the decreased Rayleigh signal at higher wavelengths, the surface albedo completely determines the result of the residue calculations, whereas in the UV aerosol effects are more pronounced. Using a reference wavelength $\lambda_{0}$ beyond the UV affects all residue calculations, whereas a reference wavelength in the UV and a second wavelength $\lambda$ in the visible or nearIR merely show surface effects. Over oceans this is less a problem, but the spectral dependence of residues of DDA and BBA over oceans was found to be more or less identical. However, over oceans a difference of absolute reflectances was observed between DDA and BBA scenes.

The above considerations led to an aerosol type classification of desert dust aerosols and biomass burning aerosols using different selection criteria over land and over oceans. Over land the residue $r_{440,380}$ and over oceans the reflectance at $380 \mathrm{~nm}$ was used to discriminate between BBA and DDA scenes with AAI >0.5. Over land this means a characterisation on the basis of geographical information, because actually vegetated land is distinguished from desert surfaces: the surface albedo dominates the residue even at these wavelengths. Over the oceans the absolute value of the reflectances at $380 \mathrm{~nm}$ of BBA scenes is highly variable, and the current selection cri-
ACPD

6, 1321-1353, 2006

\section{GOME temporal and spectral aerosol variation}

M. de Graaf et al.

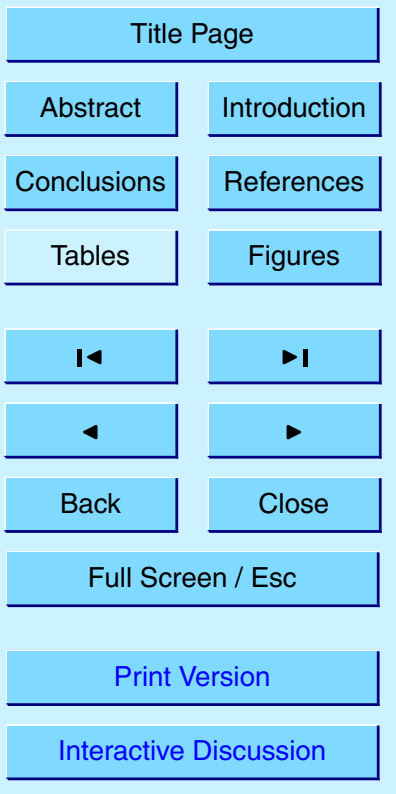

EGU 
terion misses about $48 \%$ of the BBA scenes, classifying them as DDA scenes. An aerosol type classification on the basis of the above criteria is of limited use. However, the analysis of African summer aerosol scenes showed that over oceans high reflectance aerosol scenes are caused by biomass burning aerosols.

$5 \quad$ More detailed spectra of DDA scenes, as e.g. provided by SCIAMACHY, may help to identify spectral fingerprints of desert dust. The high variability of biomass burning aerosols suggests that a more elaborate study of cloud contaminated and cloud-free BBA scenes is needed to gain information on the actual spectral fingerprints of the biomass burning aerosols themselves.

10 Acknowledgements. This work was financed by the Netherlands Agency for Aerospace Programmes (NIVR) SCIAMACHY validation project and DAEDALUS, project number EVK2-CT2002-00174. Deutscher Wetterdienst (DWD, National Meteorological Service of Germany) is acknowledged for the use of their precipitation data.

\section{References}

15 Ackerman, A. S., Toon, O. B., Stevens, D. E., Heymsfield, A. J., Ramanathan, V., and Welton, E. J.: Reduction of Tropical Cloudiness by Soot, Science, 288, 1042-1047, doi:10.1126/science.288.5468.1042, 2000. 1334

Alpert, P. and Ganor, E.: Sahara mineral dust measurements from TOMS: Comparison to surface observations over the Middle East for the extreme dust storm, 14-17 March 1998, J.

20 Geophys. Res., 106, D16, doi:10.1029/2000JD900366, 2001. 1323

Bergstrom, R. W., Russell, P. B., and Hignett, P.: Wavelength Dependence of the Absorption of Black Carbon Particles: Predictions and Results from the TARFOX Experiment and Implications for the Aerosol Single Scattering Albedo, J. Atmos. Sci., 59, 567-577, doi:10.1175/1520-0469, 2002. 1324

25 Bonasoni, P., Cristofanelli, P., Calzolari, F., Bonafè, U., Evangelisti, F., Stohl, A., Sajani, S. Z., van Dingenen, R., Colombo, T., and Balkanski, Y.: Aerosol-ozone correlations during dust transport episodes, Atmos. Chem. Phys., 4, 1201-1215, 2004, SRef-ID: 1680-7324/acp/2004-4-1201.

ACPD

$6,1321-1353,2006$

GOME temporal and spectral aerosol variation

M. de Graaf et al.

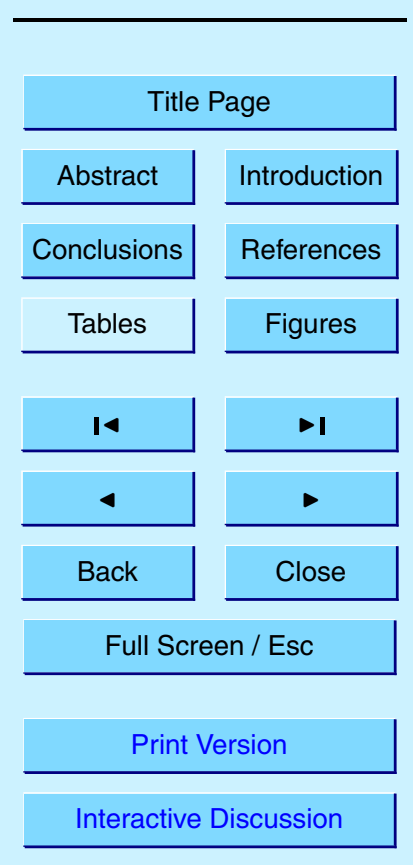

EGU 
Burrows, J. P., Weber, M., Buchwitz, M., Rozanov, V., Ladstätter-Weißenmayer , A., Richter, A., DeBeek, R., Hoogen, R., Bramstedt, K., Eichmann, K.-U., Eisinger, M., and Perner, D.: The Global Ozone Monitoring Experiment (GOME): Mission Concept and First Scientific Results, J. Atmos. Sci., 56, 151-175, doi:10.1175/1520-0469, 1999. 1324

5 Chiapello, I., Prospero, J. M., Herman, J. R., and Hsu, N. C.: Detection of mineral dust over the North Atlantic Ocean and Africa with the Nimbus 7 TOMS, J. Geophys. Res., 104, D8, doi:10.1029/1998JD200083, 1999. 1323

Colarco, P. R., Toon, O. B., Torres, O., and Rasch, P. J.: Determining the UV imaginary index of refraction of Saharan dust particles from Total Ozone Mapping Spectrometer data using a three-dimensional model of dust transport, J. Geophys. Res., 107, D16, doi:10.1029/2001JD000903, 2002. 1323

Darmenova, K., Sokolik, I. N., and Darmenov, A.: Characterization of east Asian dust outbreaks in the spring of 2001 using ground-based and satellite data, J. Geophys. Res., 110, D02204, doi:10.1029/2004JD004842, 2005. 1323, 1329

De Graaf, M. and Stammes, P.: SCIAMACHY Absorbing Aerosol Index. Calibration issues and global results from 2002-2004, Atmos. Chem. Phys., 5, 2385-2394, 2005, SRef-ID: 1680-7324/acp/2005-5-2385. 1323, 1326, 1339

De Graaf, M., Stammes, P., Torres, O., and Koelemeijer, R. B. A.: Absorbing Aerosol Index: Sensitivity Analysis, application to GOME and comparison with TOMS, J. Geophys. Res., 110, D01201, doi:10.1029/2004JD005178, 2005. 1322, 1323, 1325, 1326, 1327, 1328, 1338

Dubovik, O., Holben, B., Eck, T. F., Smirnov, A., Kaufman, Y. J., King, M. D., Tanré, D., and Slutsker, I.: Variability of Absorption and Optical Properties of Key Aerosol Types Observed in Worldwide Locations, J. Atmos. Sci., 59, 590-608, doi:10.1175/1520-0469, 2002. 1324

Duncan, B. N., Bey, I., Chin, M., Mickley, L. J., Fairlie, T. D., and Martin, R. V.: Indonesian wildfires of 1997: Impact on tropospheric chemistry, J. Geophys. Res., 108, D154458, doi:10.1029/2002JD003195, 2003. 1328

Gleason, J. F., Hsu, N. C., and Torres, O.: Biomass burning smoke measured using backscattered ultraviolet radiation: SCAR-B and Brazilian smoke interannual variability, J. Geophys.

$30 \quad$ Res., 103, D24, doi:10.1029/98JD00160, 1998. 1323

Goloub, P. and Arino, O.: Verification of the consistency of the POLDER aerosol index over land with ATSR-2/ERS-2 fire products, Geophys. Res. Lett., 27, 24, doi:10.1029/1999GL010911, 2000. 1323

ACPD

6, 1321-1353, 2006

GOME temporal and spectral aerosol variation

M. de Graaf et al.

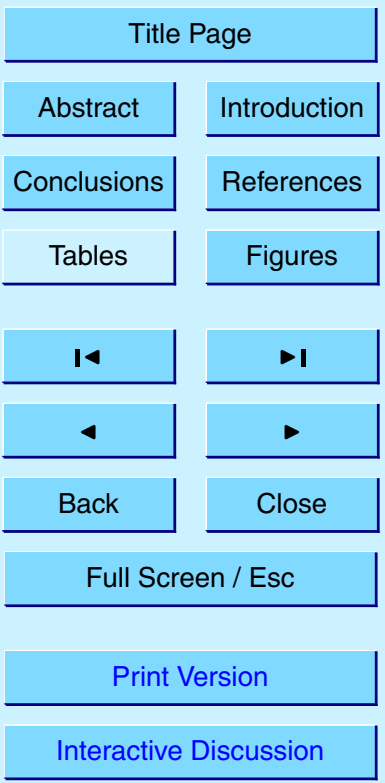

EGU 
Hansen, J., S., M., Lacis, A., and Ruedy, R.: The missing climate forcing, Phil. Trans. Royal Soc. London B, 352, 231-240, 1997. 1334

Herman, J. R., Bhartia, P. K., Torres, O., Hsu, C., Seftor, C., and Celarier, E. A.: Global distributions of UV-absorbing aerosols from NIMBUS 7/TOMS data, J. Geophys. Res., 102, D14, doi:10.1029/96JD03680, 1997. 1322, 1323, 1325, 1328, 1331

Hsu, N. C., Herman, J. R., Bhartia, P. K., Seftor, C. J., Torres, O., Thompson, A. M., Gleason, J. F., Eck, T. Y. F., and Holben, B. N.: Detection of biomass burning smoke from TOMS measurements, Geophys. Res. Lett., 23, 7, doi:10.1029/96GL00455, 1996. 1323, 1326

Hsu, N. C., Herman, J. R., Gleason, J. F., Torres, O., and Seftor, C. J.: Satellite Detection of Smoke Aerosols Over A Snow/lce Surface By TOMS, Geophys. Res. Lett., 26, 8, doi:10.1029/1999GL900155, 1999a. 1323

Hsu, N. C., Herman, J. R., Torres, O., Holben, B. N., Tanré, D., Eck, T. F., Smirnov, A., Chatenet, B., and Lavenu, F.: Comparison of the TOMS aerosol index with Sunphotometer aerosol optical thickness: Results and applications, J. Geophys. Res., 104, D6, doi:10.1029/1998JD200086, 1999b.

Janicot, S., Harzallah, A., Fontaine, B., and Moron, V.: West African Monsoon Dynamincs and Eastern Equatorial Atlantic and Pacific SST Anomalies, J. Climate, 11, 1874-1882, 1998. 1330

Kaufman, Y. J., Hobbs, P. V., Kirchhoff, V. W. J. H., Artaxo, P., Remer, L. A., Holben, B. N., King, M. D., Ward, D. E., Prins, E. M., Longo, K. M., Mattos, L. F., Nobre, C. A., Spinhirne, J. D., Ji, Q., Thompson, A. M., Gleason, J. F., Christopher, S. A., and Tsay, S.-C.: Smoke, Clouds, and Radiation - Brazil (SCAR-B) experiment, J. Geophys. Res., 103, D24, doi:10.1029/98JD02281, 1998. 1329

Kaufman, Y. J., Koren, I., Remer, L. A., Tanré, D., Ginoux, P., and Fan, S.: Dust transport and deposition observed from the Terra-Moderate Resolution Imaging Spectroradiometer (MODIS) spacecraft over the Atlantic Ocean, J. Geophys. Res., 110, D10S12, doi:10.1029/2003JD004436, 2005. 1327

Kim, D. H., Sohn, B. J., Nakajima, T., and Takamura, T.: Aerosol radiative forcing over east Asia determined from ground-based solar radiation measurements, J. Geophys. Res., 110,

$30 \quad$ D10S22, doi:10.1029/2004JD004678, 2005. 1330, 1339

Koelemeijer, R. B. A., de Haan, J. F., and Stammes, P.: A database of spectral surface reflectivity in the range 335-772 nm derived from 5.5 years of GOME observations, J. Geophys. Res., 108, D24070, doi:10.1029/2002JD002429, 2003. 1326, 1333

ACPD

6, 1321-1353, 2006

GOME temporal and spectral aerosol variation

M. de Graaf et al.

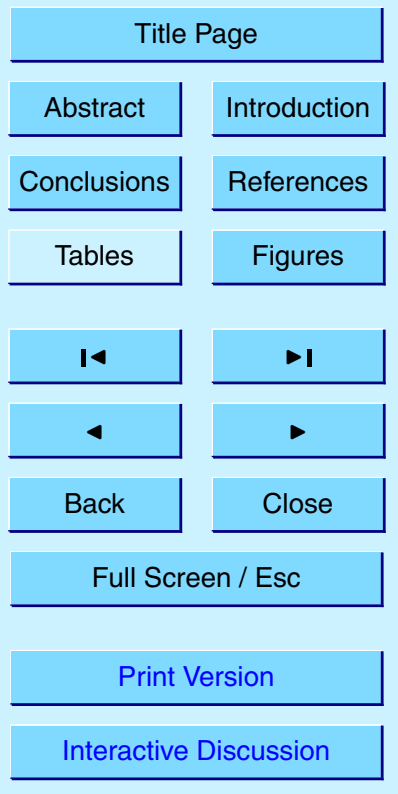

EGU 
Koren, I., Kaufman, Y. J., Remer, L. A., and Martins, J. V.: Measurement of the effect of biomass burning aerosol on inhibition of cloud formation over the Amazon, Science, 303, 1342-1345, doi:10.1126/science.1089424, 2004. 1334

McGregor, G. R. and Niewold, S.: Tropical Climatology, An Introduction to the Climates of the Low Latitudes, John Wiley \& Sons, 1998. 1330, 1332

Moulin, C. and Chiapello, I.: Evidence of the control of summer atmospheric transport of African dust over the Atlantic by Sahel sources from TOMS satellites (1979-2000), Geophys. Res. Lett., 31, L02107, doi:10.1029/2003GL018931, 2004. 1323

Pandithurai, G., Pinker, R. T., Dubovik, O., and Aro, T. O.: Remote sensing of aerosol optical characteristics in sub-Sahel, West Africa, J. Geophys. Res., 106, D22, doi:10.1029/2001JD900234, 2001. 1323

Prospero, J. M., Ginoux, P., Torres, O., Nicholson, S. E., and Gill, T. E.: Environmental characterization of global sources of atmospheric soil dust identified with the Nimbus 7 Total Ozone Mapping Spectrometer (TOMS) absorbing aerosol product, Rev. Geophys., 40, 1002, doi:10.1029/2000RG000095, 2002. 1323, 1327, 1329, 1331

Reid, J. S., Kinney, J. E., Westphal, D. L., et al.: Analysis of measurements of Saharan dust by airborne and ground-based remote sensing methods during the Puerto Rico Dust Experiment (PRIDE), J. Geophys. Res., 108, D19, doi:10.1029/2002JD002493, 2003. 1327

Sinyuk, A., Torres, O., and Dubovik, O.: Combined use of satellite and surface observations to infer the imaginary part of the refractive index of Saharan dust, Geophys. Res. Lett., 30, 1081, doi:10.1029/2002GL016189, 2003. 1323

Spichtinger, N., Wenig, M., James, P., Wagner, T., Platt, U., and Stohl, A.: Satellite detection of a continental-scale plume of nitrogen oxides from boreal forest fires, Geophys. Res. Lett., 28, 4579-4582, doi:10.1029/2001GL013484, 2001. 1323

Tanré, D., Bréon, F. M., Deuzé, J. L., Herman, M., Goloub, P., Nadal, F., and Marchand, A.: Global observation of anthropogenic aerosols from satellite, Geophys. Res. Lett., 28, 24, doi:10.1029/2001GL013036, 2001. 1329, 1330

Torres, O., Bhartia, P. K., Herman, J. R., Ahmad, Z., and Gleason, J.: Derivation of aerosol properties from satellite measurements of backscattered ultraviolet radiation: Theoretical basis, J. Geophys. Res., 103, D14, doi:10.1029/98JD00900, 1998. 1322, 1323, 1326

Torres, O., Decae, R., Veefkind, P., and de Leeuw, G.: OMI Aerosol Retrieval Algorithm, in: OMI-EOS Algorithm Theoretical Basis Document, Chapter 4, 1-24, 2001. 1323

Torres, O., Bhartia, P. K., Herman, J. R., Sinyuk, A., Ginoux, P., and Holben, B.: A Long-Term

ACPD

6, 1321-1353, 2006

GOME temporal and spectral aerosol variation

M. de Graaf et al.

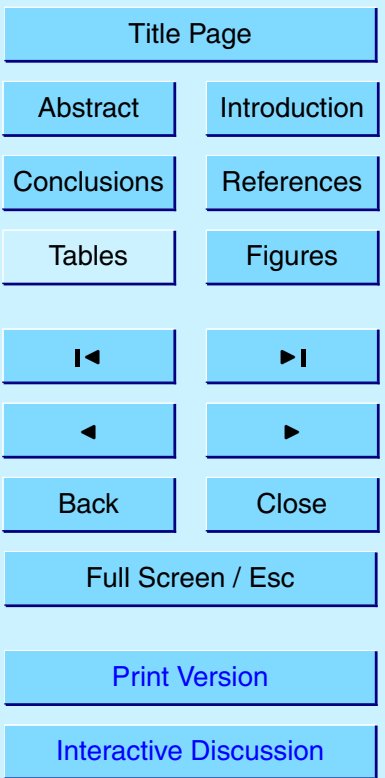

EGU 
Record of Aerosol Optical Depth from TOMS Observations and Comparison to AERONET Measurements, J. Atmos. Sci., 59, 398-413, doi:10.1175/1520-0469, 2002. 1323, 1328, 1329,1331

Tsunematsu, N., Sato, T., Kimura, F., Kai, K., Kurosaki, Y., Nagai, T., Zhou, H., and Mikami, M.: 5 Extensive dust outbreaks following the morning inversion breakup in the Taklimakan Desert, J. Geophys. Res., 110, D21207, doi:10.1029/2005JD005994, 2005.

Webster, P. J.: Chap. 1: The elementary Monsoon, in: Monsoons, edited by: Fein, J. S. and Stephens, P., p. 3-32, J. Wiley \& Sons, 1987. 1330

\section{ACPD}

$6,1321-1353,2006$

GOME temporal and spectral aerosol variation

M. de Graaf et al.

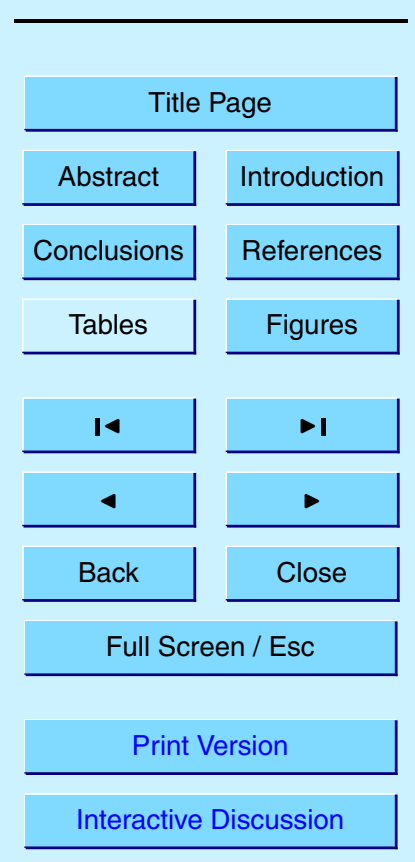




\section{ACPD}

$6,1321-1353,2006$

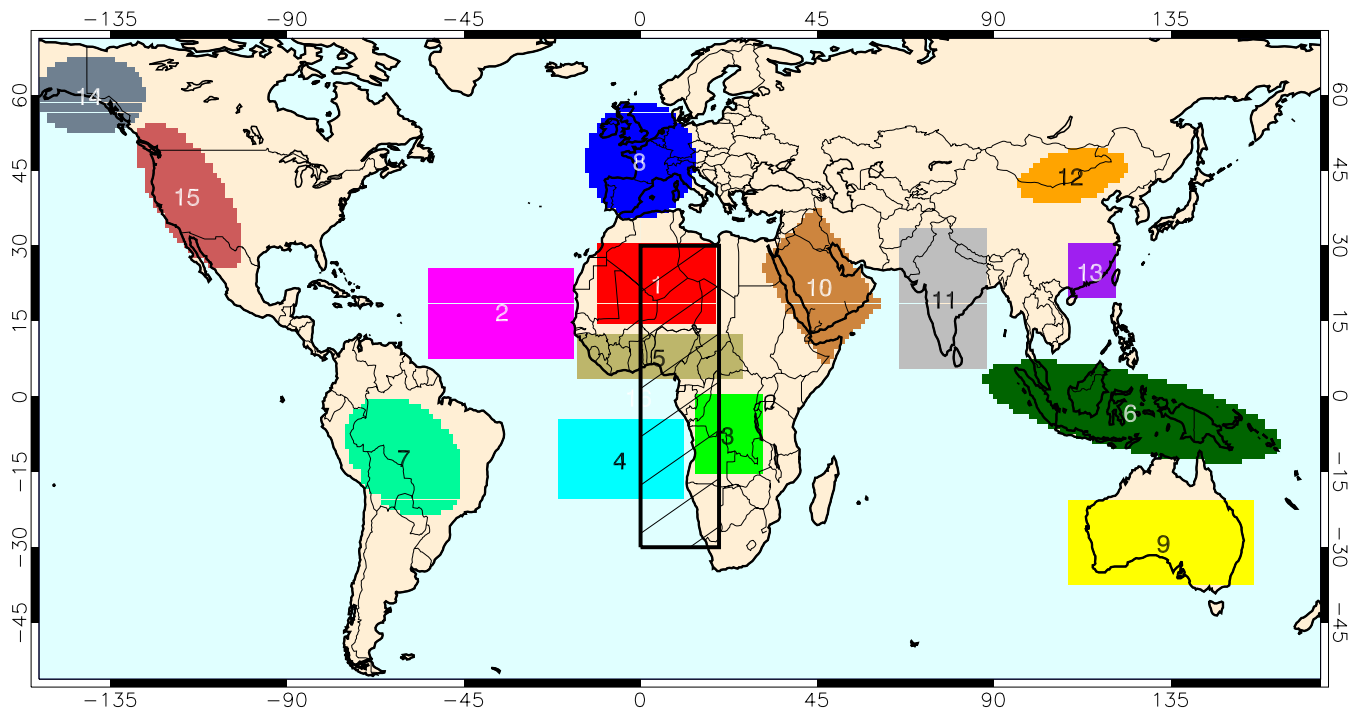

Fig. 1. Regions for which the area-averaged GOME residue $r_{335,380}$ time series was determined from July 1995 to December 2000 (coloured and numbered areas), shown in Fig. 2. The shaded area was used to determine the temporal behaviour of the zonally averaged GOME residue $r_{335,380}$, shown in Fig. 3 .

\section{GOME temporal and spectral aerosol variation}

M. de Graaf et al.

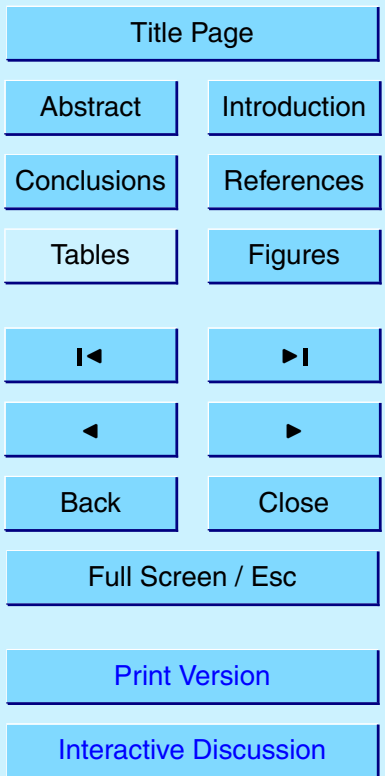



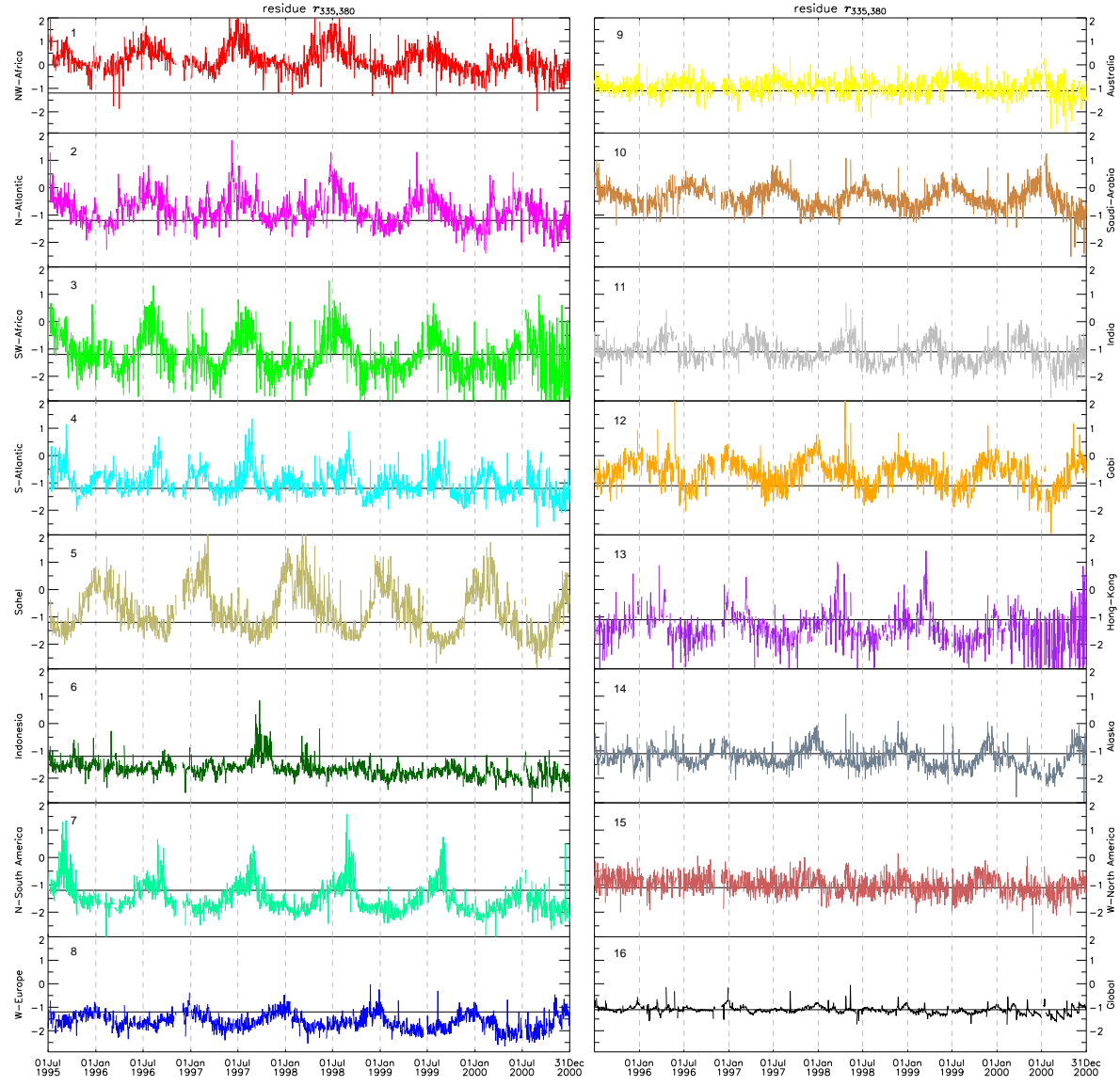

ACPD

$6,1321-1353,2006$

GOME temporal and spectral aerosol variation

M. de Graaf et al.

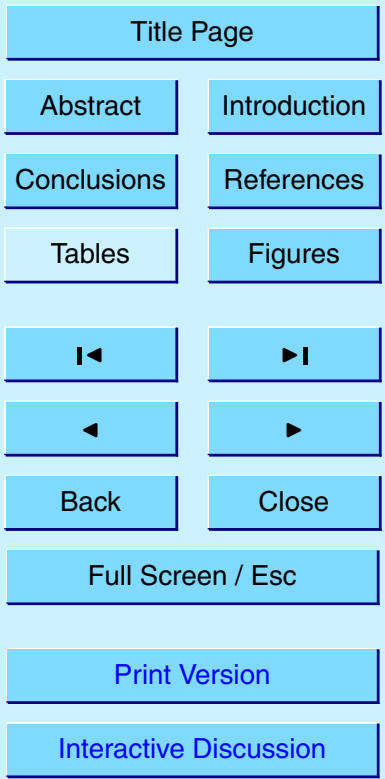

Fig. 2. Five and a half year daily GOME residue $r_{335,380}$ time series from July 1995 to December 2000 averaged over the areas indicated in Fig. 1. The solid black line shows the global average GOME residue of -1.2 .

EGU 


\section{ACPD}

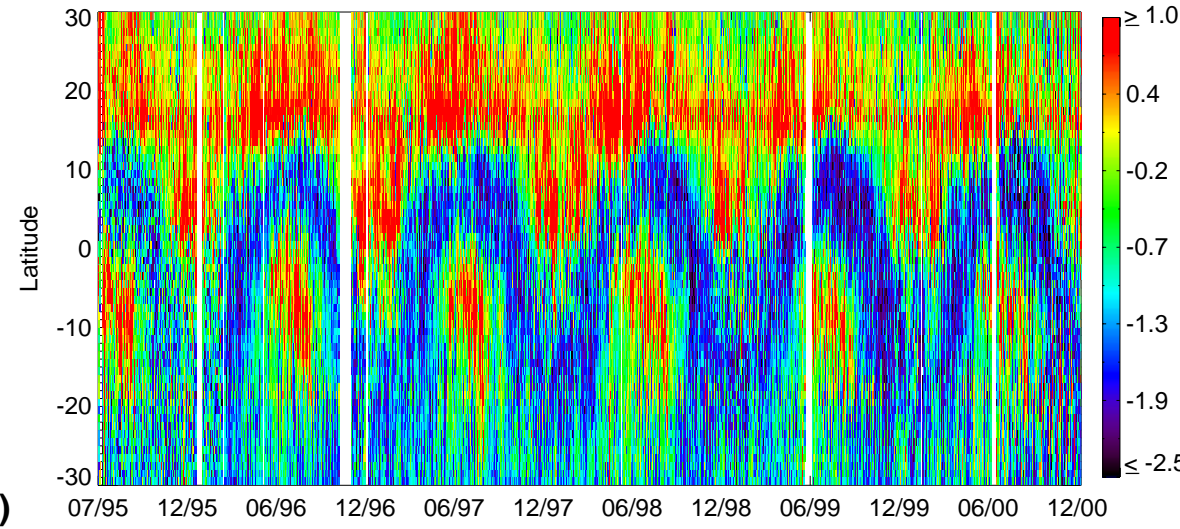

$6,1321-1353,2006$

(a)

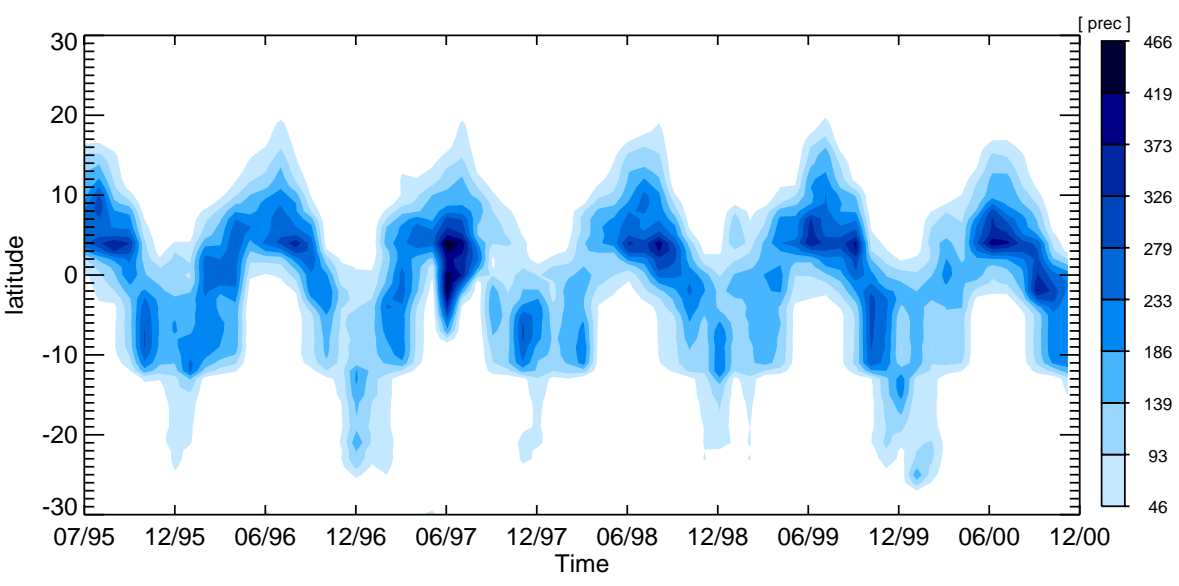

\section{GOME temporal and spectral aerosol variation}

M. de Graaf et al.

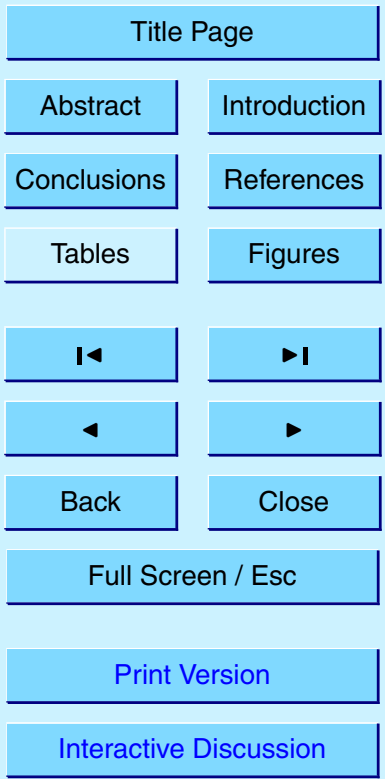

Fig. 3. (a) Zonally averaged GOME residue $r_{335,380}$ of the shaded area in Fig. 1 for each day between July 1995 and December 2000. (b) One by one degree gridded and monthly averaged GPCC precipitation in the shaded area in Fig. 1, averaged zonally, from July 1995 to December 2000.

EGU 


\section{ACPD}
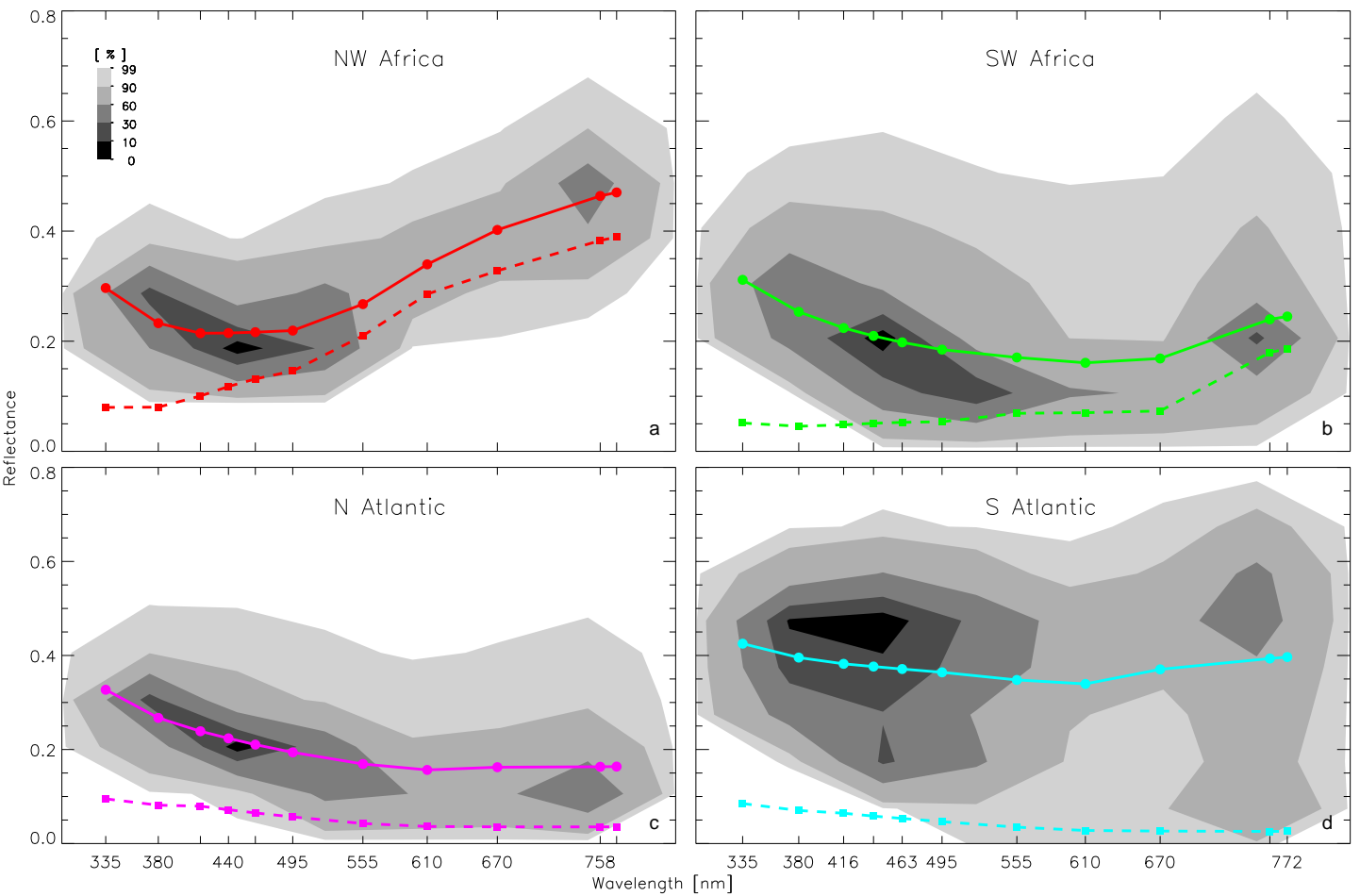

Fig. 4. Average GOME reflectance spectrum (solid line) and its spread (grey-scale contours) and average surface albedo (dashed line) at eleven wavelengths for UV-absorbing scenes with AAI $>0.5$ in June to August 1997 from areas 1-4 in Fig. 1: (a) northwest Africa (red), (b) southwest Africa (green), (c) North Atlantic Ocean (magenta), and (d) South Atlantic Ocean (cyan).

$6,1321-1353,2006$

GOME temporal and spectral aerosol variation

M. de Graaf et al.

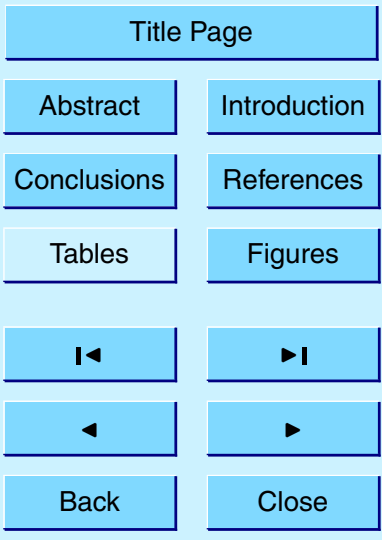

Full Screen / Esc

Print Version

Interactive Discussion

EGU 


\section{ACPD}
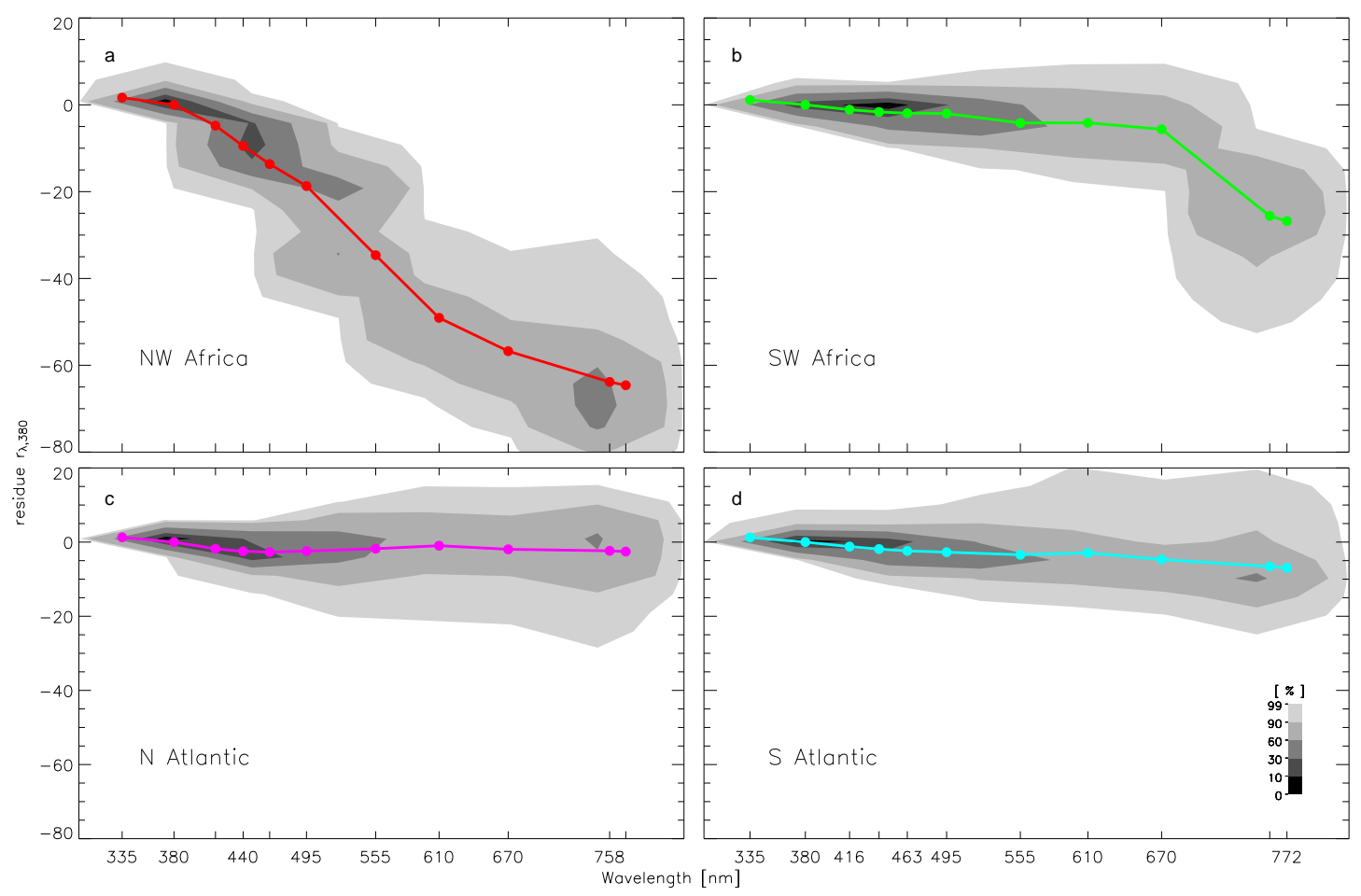

$6,1321-1353,2006$

GOME temporal and spectral aerosol variation

M. de Graaf et al.

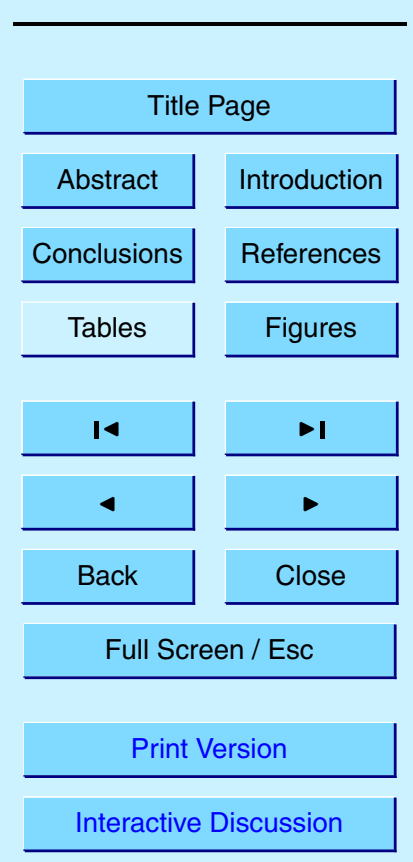

Fig. 5. Average GOME residue spectrum $r_{\lambda, 380}$ (solid line) and its spread (grey-scale contours) at eleven wavelengths for UV-absorbing scenes with AAI >0.5 in June to August 1997 from areas 1-4 in Fig. 1: (a) northwest Africa (red), (b) southwest Africa (green), (c) North Atlantic Ocean (magenta), and (d) South Atlantic Ocean (cyan). 


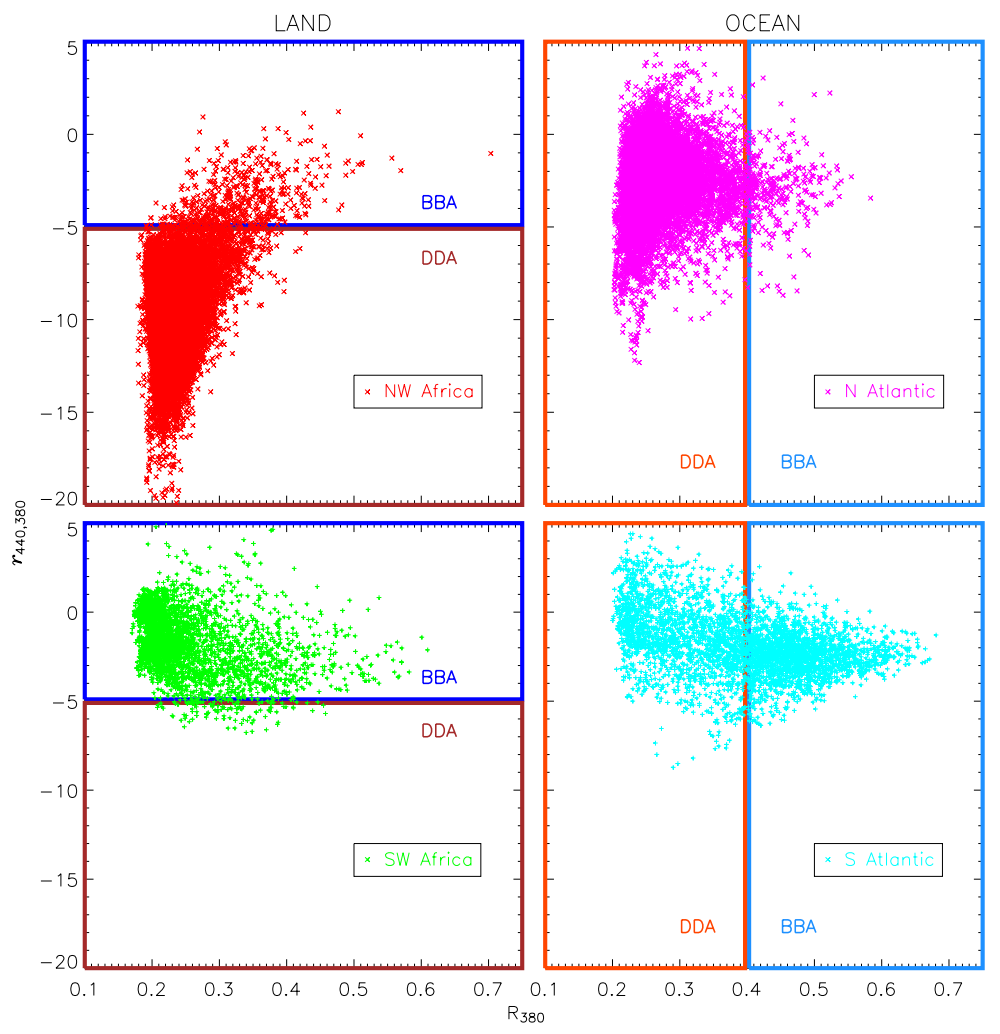

Fig. 6. Scatter diagrams of $r_{440,380}$ versus $R_{380}$ for scenes with AAI $>0.5$ in the areas 14 of Fig. 1, left from land, right from ocean areas; GOME pixels from northwest Africa are plotted in red, pixels from southwest Africa are plotted in green, GOME ocean pixels from the North Atlantic Ocean are plotted in magenta and pixels from the South Atlantic Ocean are plotted in cyan. $98 \%$ of the red pixels have an $r_{440,380}<-5 ; 97 \%$ of the green pixels have an $r_{440,380}>-5 ; 98 \%$ of the magenta pixels have a reflectance $R_{380}<0.4 ; 52 \%$ of the cyan pixels have a reflectance $R_{380}>0.4$.
ACPD

$6,1321-1353,2006$

GOME temporal and spectral aerosol variation

M. de Graaf et al.

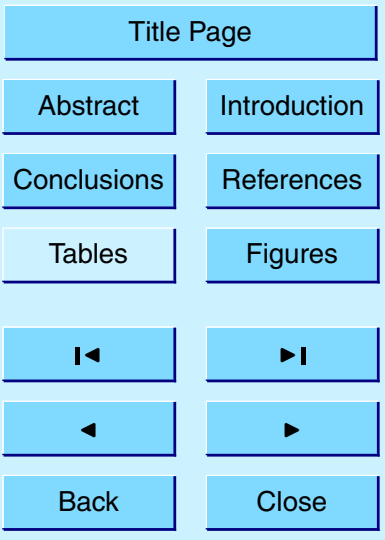

Full Screen / Esc

Print Version

Interactive Discussion 


\section{ACPD}

$6,1321-1353,2006$

\section{GOME temporal and spectral aerosol variation}

M. de Graaf et al.

(a)

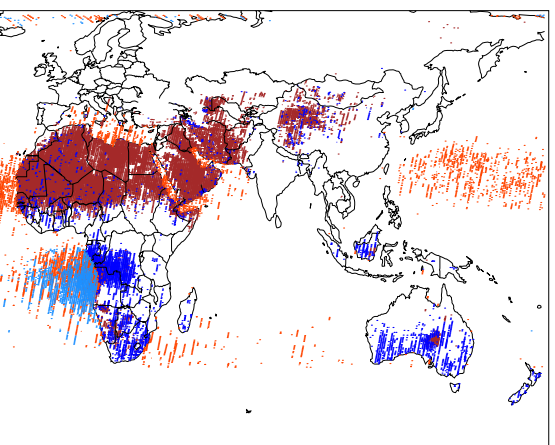

焦。

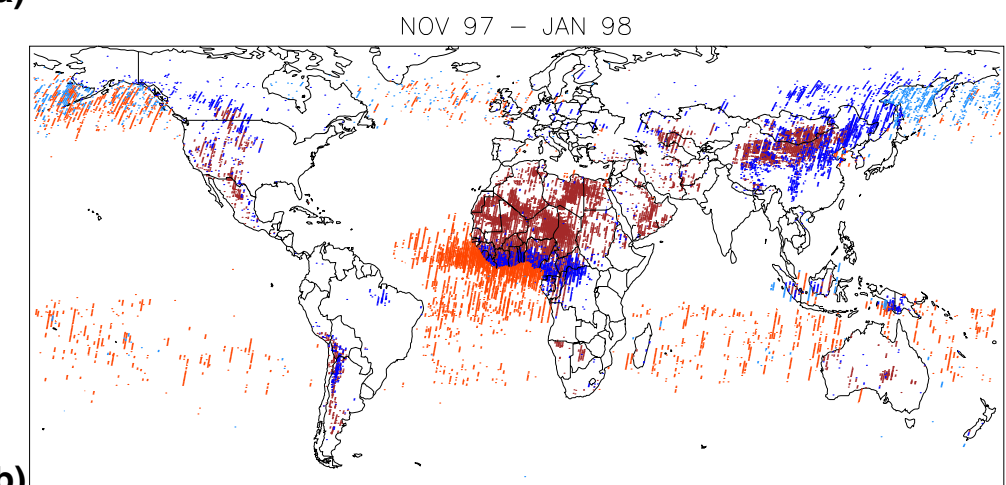

(b)

Fig. 7. (a) World plot of all GOME pixels from June 1997 to August 1997 having AAI $>0.5$ (containing UV-absorbing aerosols). Land pixels with a residue $r_{440,380}$ lower than -5 are plotted in brown (assumed to be desert dust aerosols), land pixels with a residue $r_{440,380}$ greater than -5 are plotted in dark blue (assumed to be biomass burning aerosols), ocean pixels with a reflectance at $380 \mathrm{~nm} R_{380}$ lower than 0.4 are plotted in orange (assumed to be desert dust aerosols) and ocean pixels with a $R_{380}$ higher than 0.4 are plotted in light blue (assumed to be biomass burning aerosols). (b) Same as (a), but from November 1997 to January 1998.

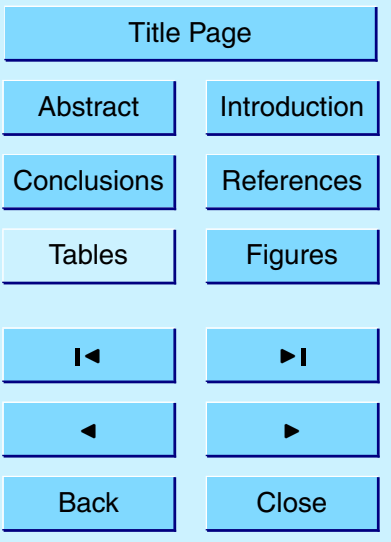

Full Screen / Esc

Print Version

Interactive Discussion 